\title{
فكر حركات الإسلام السياسي ، دراسة في المقومات والمعوقات
}

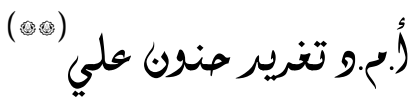

(...م.و طارق عبر (لحافظ (لزبيري)(ه)

ان تناول فكر حركات الاسلام السياسي ليس بالامر اليسير من إذ تعدد اتجاهاتها من جهة وكثرة التاويلات التي طرحت بصددها من جهة اخرى إذ اخذ

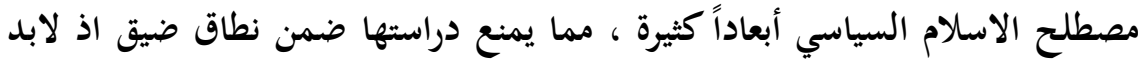

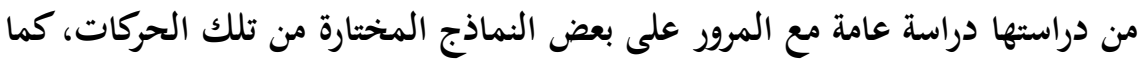

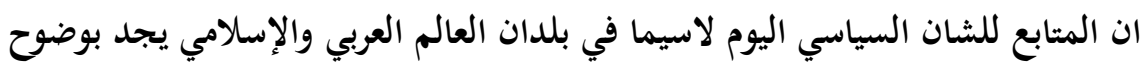

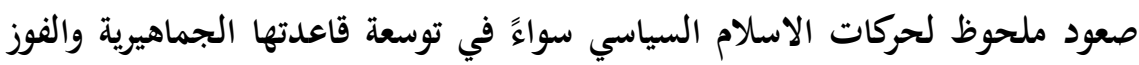

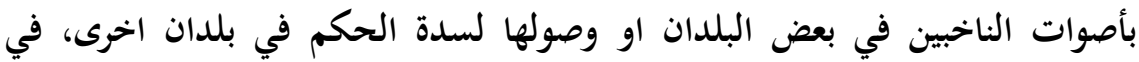
مقابل انحسار وتراجع للتيارات السياسية المنافسة (التيارات الليبرالية والاشتراكية والقومية).

وعلى الرغم من كل المقومات التي تساهم في نجاح تلك الحركات وتساعدها في الانتشار و الظهور ، الا ان هناك جملة من المعوقات ساهمت وتساهم في فشل بعض من تلك الحركات ولعل السبب في النجاح والفشل يتحدد بمدى افادة اي حركة

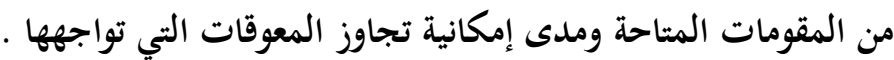
يُعد مفهوم الإسلام السياسي من المفاهيم المهمة والمتداولة في عالمنا اليوم

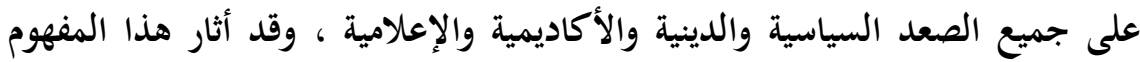

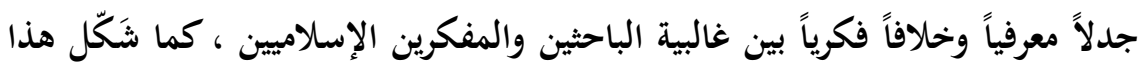
المفهوم في مراحل معينة محوراً أساسياً في التوجيه والتنظير الفكري لدى الدين الحركات السياسية الإسلامية التي ترفع شعار (الإسلام هو الحل) وشعار ( ما الحكم إلا لله 
وغيرها من الشعارات ، وأصبحت هذه الشعارات مصدرا لتوظيف الشرعية عند اغلب

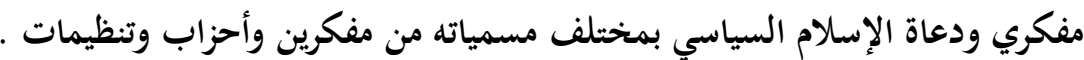
ولعل أهمية موضوع الإسلام السياسي ككل متأتية من حقيقة فاعلية معظم

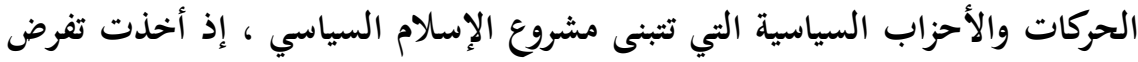
نفسها بشكل فاعل في ميدان الفكر والعمل السياسي في معظم البلدان العربية العردية

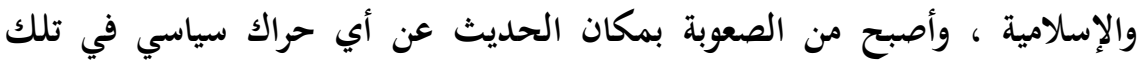
البلدان بمعزل عن حركات الإسلام السياسي ، والفاعلية لهذه الحركات السياسية ظهرت من خحلال قدرتها على تحشيد وتحريك الجماهير من جهة ، ومن خلال قدرتها على المنافسة والفوز بالانتخابات من جهة أخرى . مئى ليس هناك من شك في ان بروز حركات الإسلام السياسي ليست وليدة اللحظة ، بل يعود ظهورها عند البعض إلى ظهور الإسلام نفسه ولكنه تجلى بشكل واضح للعيان مع بداية القرن العشرين ، إلا ان ظهورها اليوم يختلف عن جميع المراحل التاريخية السابقة إذ ان هذه الحركات في اغلبها اتسمت بصفة العنف والتشديد الغير قابلة للحوار وقبول الرأي الأخر ، مما جعلها تمثل اكبر التحديات التي تواجه معظم

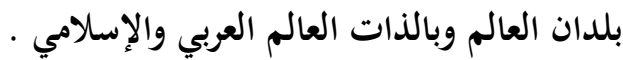
ان الأمانة العلمية والمنهجية الموضوعية تجعلنا نقول ان حركات الإسلام السياسي أخذت وتأحذ مسارين ، المسار الأول هو أسلوب العنف المسلح سبيلاً

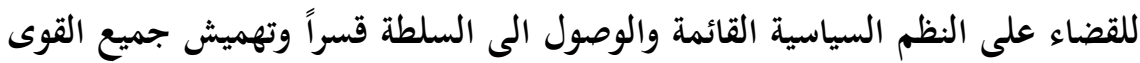
السياسية الأخرى وفي احياناً كثيرة تحاول تطبيق تصورات ورؤى غريبة عن عادات التهات وتقاليد المجتمعات الإسلامية من جهة وغريبة عن الإسلام نفسه من جهة أخرى ، أما لإنائان

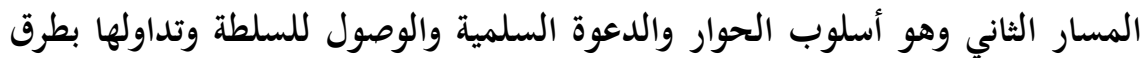
سلمية خالية من العنف ، وبغض النظر عن المسار التي تتبعه حركات الإسلام السياسي يبقى الحديث عنها بشكل موضوعي أكاديمي هو ما تبتغيه الدراسة .

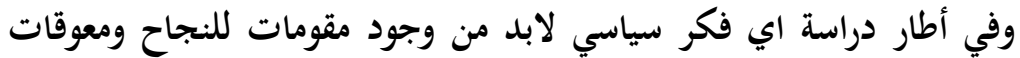
تساهم في الفشل ، والتي تكون نسبية في اغلبها لان في عالم السياسة لا يوجد نجاح 
تام ولا فشل مطلق ، بل توجد مقومات للنجاح البعض يستثمرها ليحقق النجاح برغم وجود المعوقات إلى جانبها والبعض الأخر يعمل العكس . ولغرض التعرف على فكر حركات الإسلام السياسي من إذ مقومات النجاح وأسباب الفشل ، تنطلق الدراسة من فرضية مفادها ( ان فكر حركات الإسلام السياسي والمتمثل بمفكري وقادة الحركات السياسية الإسلامية لم يكن فكراً سياسياً واقعياً بقدر

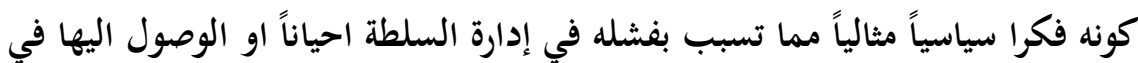
أحيان اخرى )

ولغرض التأكد من صحة الفرضية من عدمه قسمت الدراسة إلى أربعة محاور، يتناول المحور الأول مفهوم الإسلام السياسي ، أما المحور الثاني فيبحث في حركات الإسلام السياسي في حين المحور الثالث جاء تحت عنوان حركات الإسلام السياسي مقومات النجاح وأسباب الفشل ، وقد تناولنا في المحور الرابع موضوع حركات الإسلام السياسي قراءة في ممارستها للسلطة . المحور الاول : مفهوم الاسلام السياسي.

إن تحديد المفاهيم والمصطلحات في أي بحث علمي أكاديمي أمر ضروري

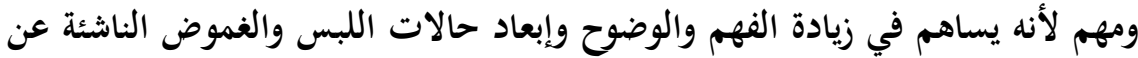
تباين الفهم من جهة ، وتحسين سبل التواصل المعرفي الدقيق بين المتخاطبين من جهة

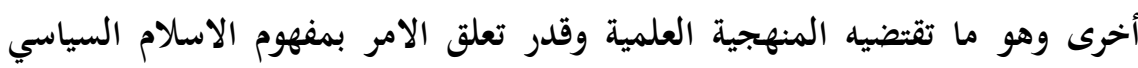
ودلالاته اللغوية والاصطلاحية فلابد من القول ابتدأ ان المفهوم تم استعماله اعلامياً وسياسياً وكانه مفهوماً واحداً ولكن اكاديمياً يجب التعامل معه بصفته مفهوما مركباً من مفردتين (الاسلام والسياسة) لذا معرفة هاتين المفردتين كفيلة بمعرفة المراد بالاسلام

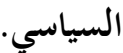

ان الاسلام اليوم كدين اصبح من الديانات الواسعة والمنتشرة في العالم إذ بلغ الذين يدينون به اكثر من مليار ونصف المليار مسلم ومسلمة، ومعناه المفاهيمي

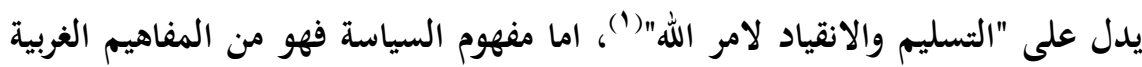


الدالة على الحكم والسلطة وادارة الدولة ، فتعرف السياسة بانها "فن ممارسة القيادة

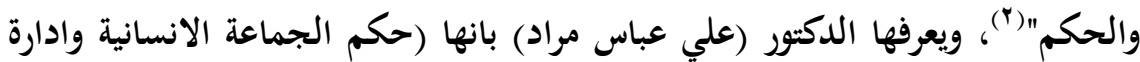
شؤونها، واتخاذ القرارات العامة المتعلقة بحماية وجودها وادامة قيمها وضمان مصالحها وتحقيق اهدافها و استثمار قدراتها وتنظيم علاقاتها وتفاعلاتها وتوجيهها في الداخل والخارج) (").

ويميز (محمد جمال باروت) بين ثلاثة مستويات اساسية في ممارسة الاسلام

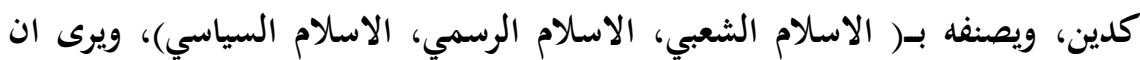

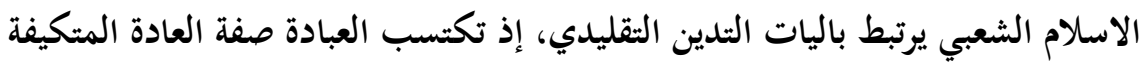
مع تقاليد المجتمع المحلي، في حين ينظر الى الاسلام الرسمي بانه المؤسسة الفقهية

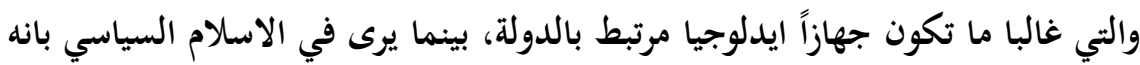

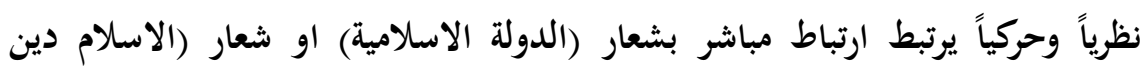

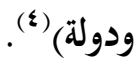

لذلك فقد اطلق لفظ الاسلام السياسي على كل من يؤمن بان الاسلام اهتم

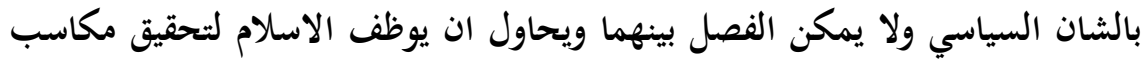

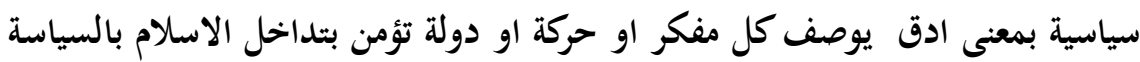

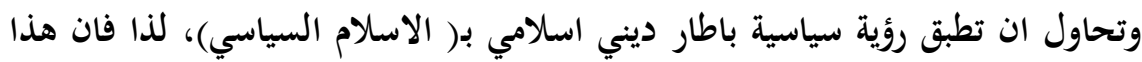

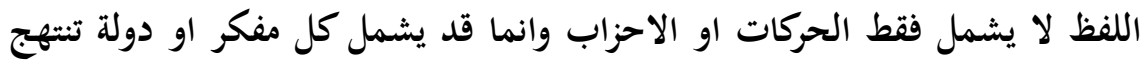

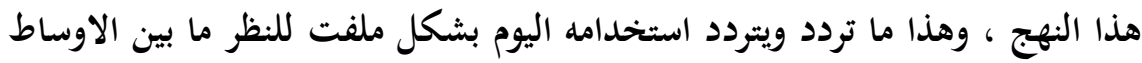
الاكاديمية والسياسية والاعلامية (اصدار كتب، اقامة مؤتمرات ونداوات، لقاءات تلفزيونية وصحفية وغيرها) اصطلاحاً عرف الإسلام السياسي تعريفات متعددة ومختلفة ، فهناك من عرفه بعده ( تعبيراً عن الحركات والقوى التي تصبو الى تطبيق الشريعة الاسلامية منهجاً

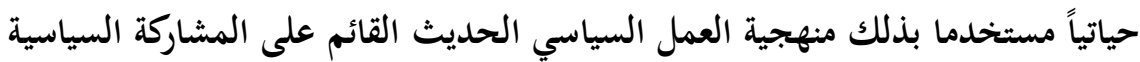

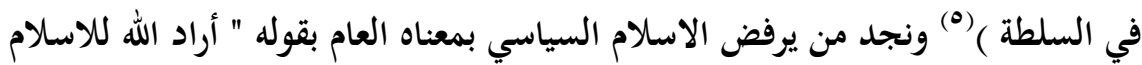

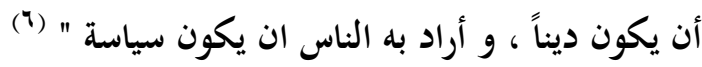


ويذهب البعض ومنهم ( عزمي بشارة ) الى اعتبار ان " الاسلام السياسي نتاج

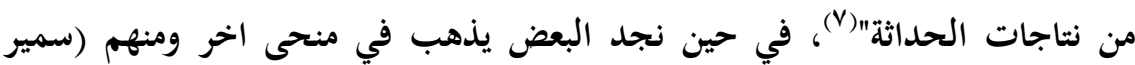

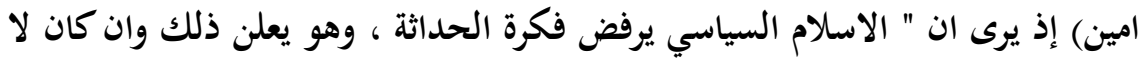

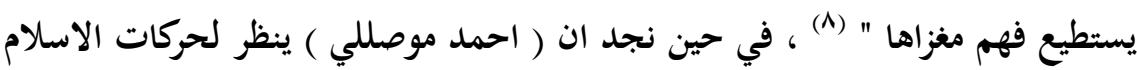

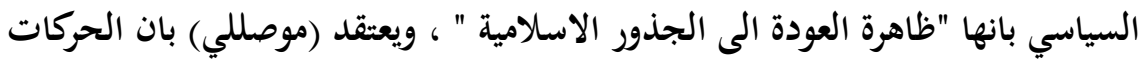
الاسلامية وعلى مر العصور هدفت الى" تحرير الفكر الاسلامي و المجتمع الاسلامي من شوائب الفكر والسلوك والى تحرير الفكر الاسلامي من جموده و و الواقع من (9) ف (9)

وهناك من يرى بان مصطلح ( الاسلام السياسي ) يجمع كل الجماعات التي تتخذ من الاسلام كدين في تحركها السياسي أيديولوجية و تسعى إلى تطبيقه عند

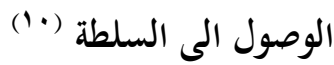
على الرغم من عدم وجود تعريف جامع ومانع لمفهوم الإسلام السياسي لكن بالامكان تعريفه بانه مجموعة من الافكار والاهداف السياسية المستوحاة من الشريعة الاسلامية والتي يستخدمها مجموعة من المسلمين بالذات الذين يؤمنون بان الاسلام ليس عبارة عن ديانه روحانية عقائدية فحسب وانما عبارة عن نظام سياسي واقتصادي واجتماعي وقانوني يصلح لبناء مؤسسات الدولة لا يمكن للمسلم تجاوزه .

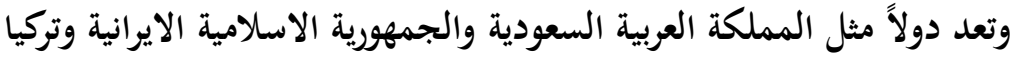
في عهد اردوغان ونظام طالبان السابق في افغانستان وغيرها امثلة واضحة ممكن ان تعبر عن مشروع الاسلام السياسي بجانبه المؤسساتي ، وتعد حركات وأحزاب إسلامية مثل حركة الاخوان المسلمين في مصر و حزب العدالة والتنمية في تركيا و الأحزاب الإسلامية في العراق وجبهة الانقاذ في الجزائر ، وحركة النهضة في تونس و حركة

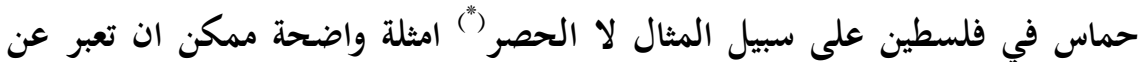
مشروع الإسلام السياسي بجانبه الحزبي والتنظيمي ، الا ان تلك الدول وتلك الاحزاب والحركات يرفضون في اغلبهم مصطلح الاسلام السياسي ويستخدمون عوضاً عنه مصطلحات اخرى مثل ( الحكم بالشريعة ، الحاكمية الالهية ، وغيرها) ويعتقدون ان 
مفهوم الاسلام السياسي هو بمثابة اختزال للاسلام بالسياسية هذا من جهة ومن جهة اخرى يرفضونه باعتباره مفهوم غربي اطلقه الغرب على الحركات والاحزاب السياسية الاسلامية ولم يولد من رحم واقع الدول العربية والاسلامية . اولا: الاتجاه الفكري الاسلامي الذي يرفض تسمية الاسلام السياسي . ويذهب اتباع هذا الاتجاه الى رفض اطلاق تسمية الاسلام السياسي على

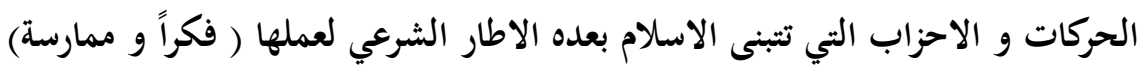

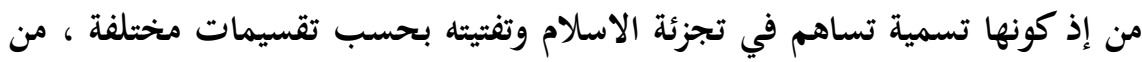

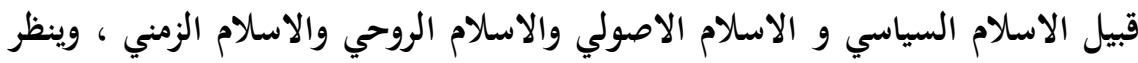

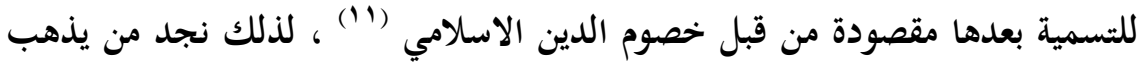
الى حد تحريم المصطلح من إذ ان المصطلح يندرج في اطار اخذ جزء من الاسلام

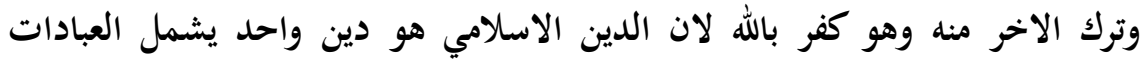

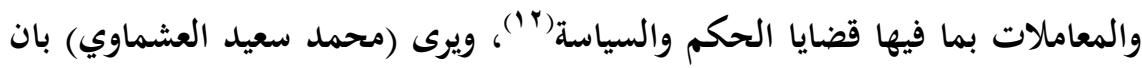
المفهوم يؤدي الى الخلط بين الدين والسياسة ويؤدي بالتالي بالضرر بالاثنان معاً، وابرز الإضرار تفرقة المسلمين الى طوائف وملل هذا من جهة ومن جهة اخرى استعمال

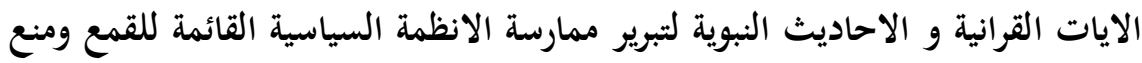

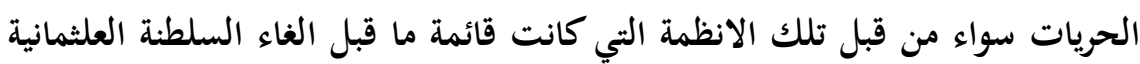

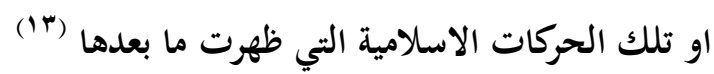

ويذهب (هشام جعفر) الى القول بان الحديث عن حركة الاسلام السياسي

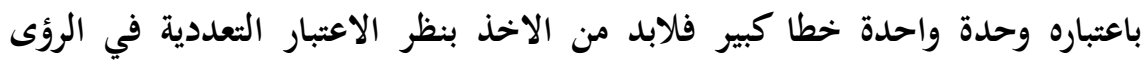
والتصورات و الاستراتيجيات التي تحملها تلك الحركات، ويرى (هشام جعفر) ان اضفاء صبغة السياسي على الاسلام يؤدي الى خلط وتشويش لانه ينتج مصطلح يجزئ

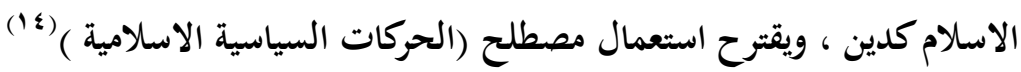


ثانياً: الاتجاه الفكري الاسلامي الذي يقبل بتسمية الاسلام السياسي .

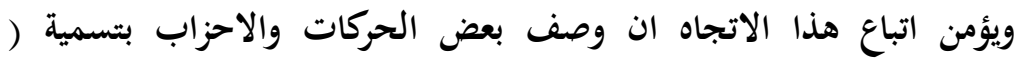
الاسلام السياسي) ليس فيه اي انتقاص من الدين الاسلام ومن ودوره في الحياة بل العكس إذ هناك من يرى ان " الاسلام السياسي هو صناعة راي عام مستنير ، يجمع لهع

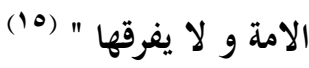

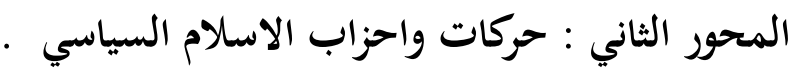
اختلفت الدراسات التي حاولت ان تؤشر بدايات ظهور حركات الاسلام

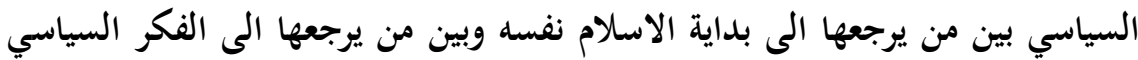

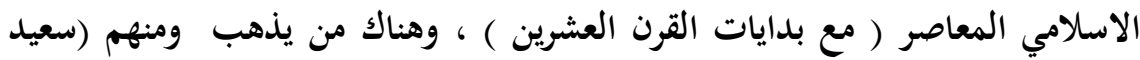

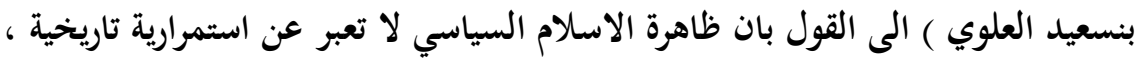
ولا تشكل تواصلا مع تراث هذه الامة بقدر ما هي ظاهرة مرتبطة بالحياة العربية

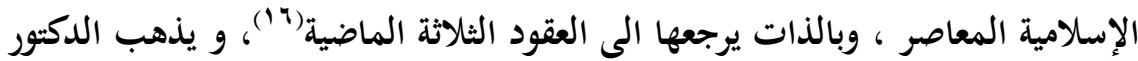
(حسين سعد) الى ان تاصيل مصطلح الاسلام السياسي يعود الى بيئة محمد عبده ومحمد رشيد رضا، والذي يجعل من الاسلام ركيزة العمل السياسي والمواقف السياسية

وفي هذا الاطار فقد اتخذت ظاهرة الاسلام السياسي تسميات عديدة لكن في غالبها الاعم تاخذ نفس المعنى مثل ( الصحوة الاسلامية ، التجديد الاسلامي ، الانبعاث الاسلامي ، النهضة الاسلامية ، الظاهرة الاسلامية ، الاسلام الراديكالي ،

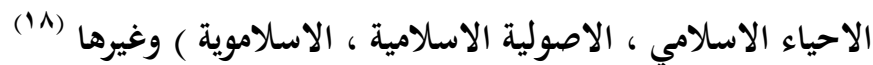
ومن الاخطاء الشائعة في الخطاب السياسي المعاصر انه عندما يُذكر مفهوم

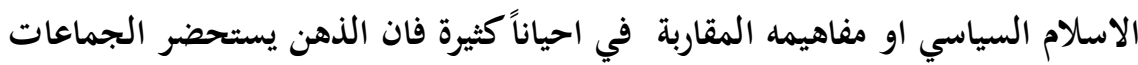
الدينية المتطرفة و يقتصر عليها حصراً في حين ان الاسلام السياسي في حقيقته يشمل

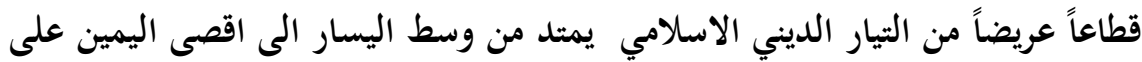

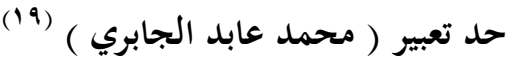


لكن الذي يهمنا في هذه الدراسة هو تناول هذه الظاهرة بوصفها حركة اجتماعية تعمل في شكل مجموعات تنتسب للدين الاسلامي وترفع شعار ( الاسلام

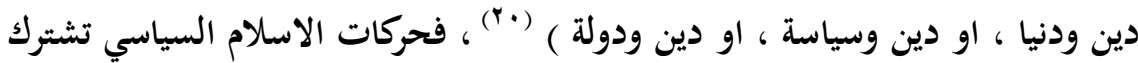

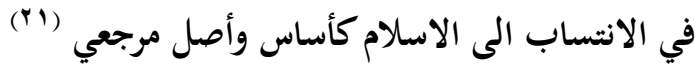
اختلفت الدراسات في توصيف الاتجاهات السياسية التي تتبنى مشروع الاسلام السياسي ما بين تسيمته بحركة او حزب ، وتعرف الحركة بمعناها السياسي بانها ( التيار العام الذي يدفع طبقة من الطبقات او فئة اجتماعية معينة الى تنظيم نفسها بهدف القيام بعمل موحد لتحسين حياتها الاقتصادية او الاجتماعية او السياسية او تحسينها جميعاً ، ولكنها في الوقت نفسه اقل تماسكاً وانضباطاً من الحزب ، بهاب ، اذ

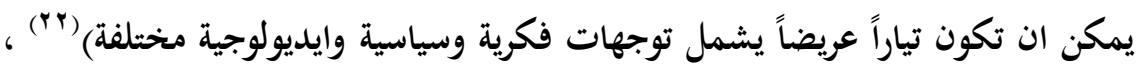

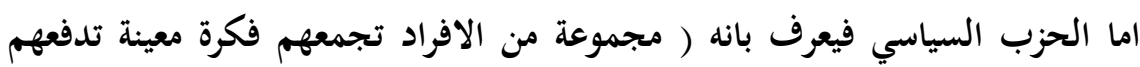
للعمل المتواصل في سبيل استلام السلطة او الاشتراك في السلطة وذلك لتحقيق

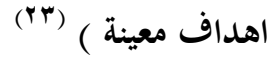

لذلك فان حركات الإسلام السياسي لا تتضمن الحركات الإسلامية التي تبتعد

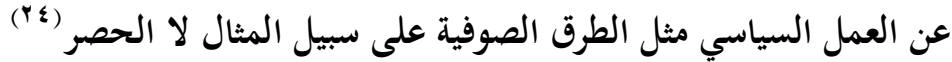

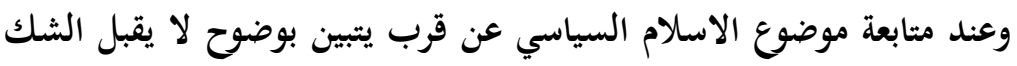

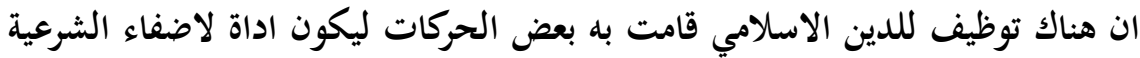

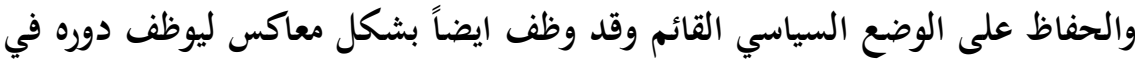

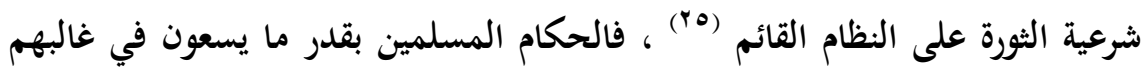

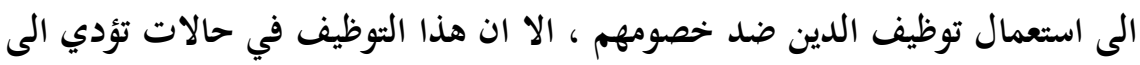

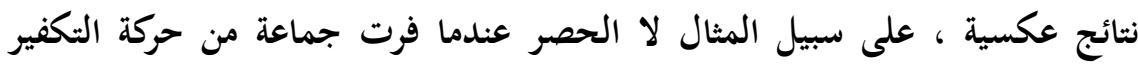

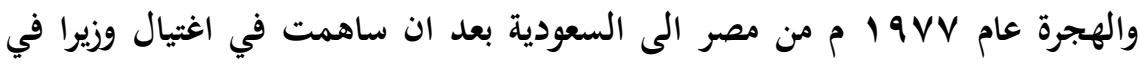

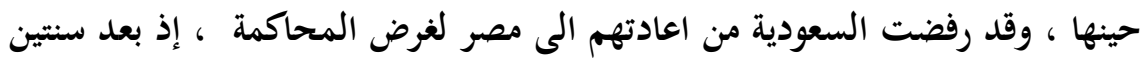

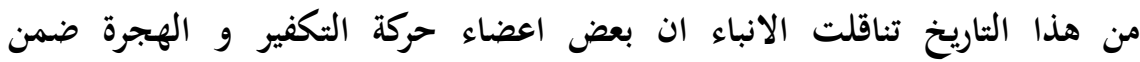

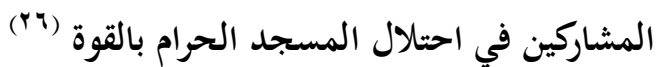


وحول الاسباب التي ساهمت بظهور حركات الاسلام السياسي فهناك عدة : اراء منها (YV)

1- الايمان بشمولية الاسلام ، باعتباره يمتلك حلول متكاملة لكل مشاكل

الحياة السياسية و الاقتصادية و الاجتماعية ، لذلك رفع شعار ( ان

الاسلام دين و دنيا ) ، لذلك نجد ان هذه المقولة اصبحت السمة

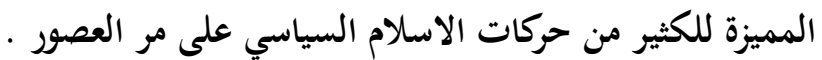

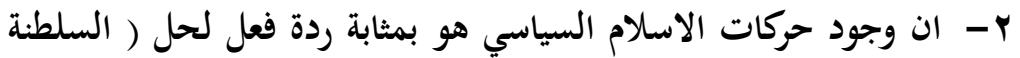

العثمانية ) التي كانت تمثل عند البعض واجهة الدولة الاسلامية القائمة

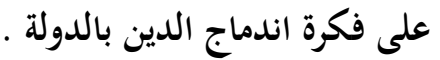

ب- الاثر الواضح لمفهوم " حاكمية الله " الذي تبناه عدد من المفكرين

المعاصرين امثال (ابو الاعلى المودودي وسيد قطب ) على الكثير من لهن

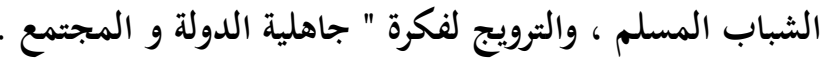

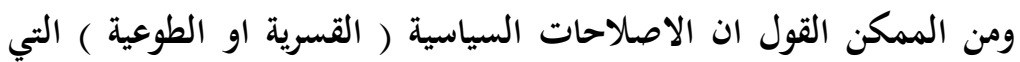

تقوم بها بعض الانظمة العربية ممكن ان تكون سبب مباشر او غير مباشر لوصول حركات الاسلام السياسي ، إذ اثبت التجارب ان اعتماد صندوق الانتخابات يساهم

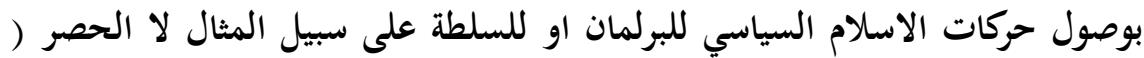

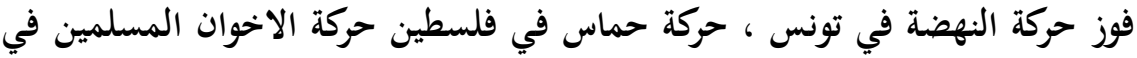
مصر وغيرها ) مما جعل الولايات المتحدة تتبع سياسة جديدة تحاول فيها تخفيف الضغط على الحكومات العربية الحاكمة في مطالبتها بالإصلاح خوفاً من صعود أمثال

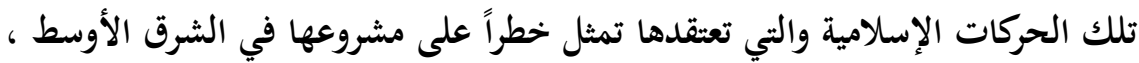

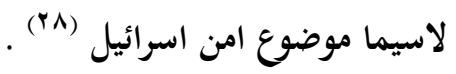

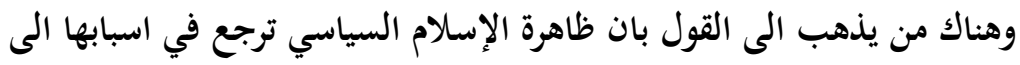

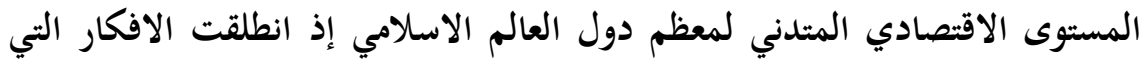

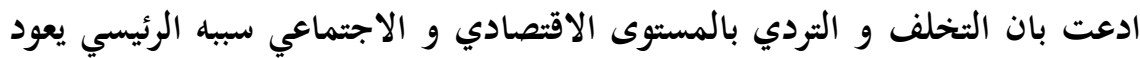

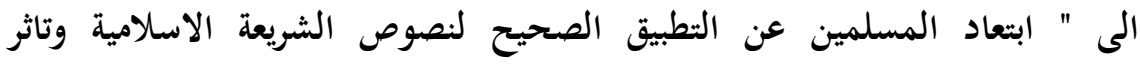


حكوماتهم بالسياسة الغربية"(9)، بمعنى ان السبب الرئيسي في هذا التخلف هو التخلي عن الاسلام كنظام شامل للحكم لمعالجة المشكلات الاقتصادية والاجتماعية . ونجد ايضا من يحدد اسباب عودة ظهور حركات الاسلام السياسي بوضوح

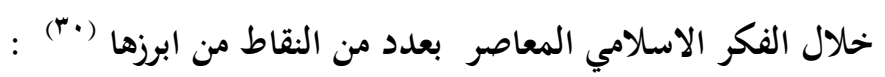
ا- واقع التكوين الثقافي للمجتمع العربي ، إذ تحتل الفكرة الدينية موقعاً متميزا في منظومة الافكار العامة السائدة . ץ- ان المسالة السياسية في الاسلام دائما هي مسالة مهمة و و معقدة

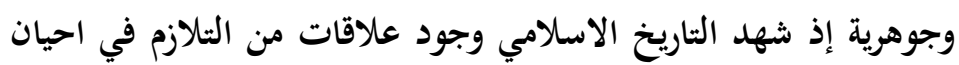
والتخاصم في احيان اخرى بين السياسة و الدين.

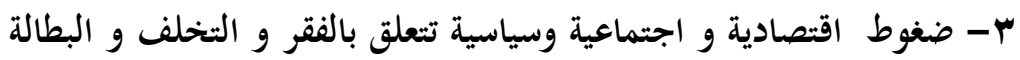

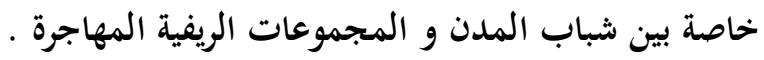
ع - ردت الفعل ضد الغزو الثقافي وثورة المعلومات والعولمة بمعناها الواسع. ويذهب الدكتور (حيدر ابراهيم علي ) الى ان نمو الحركات الاسلامية كان

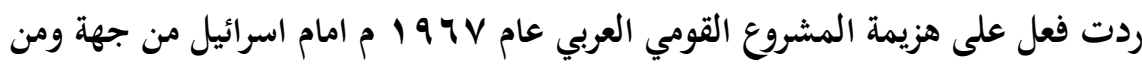

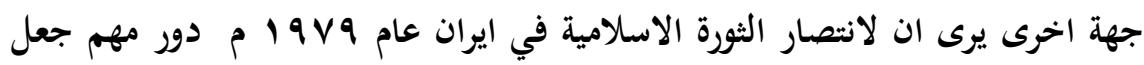

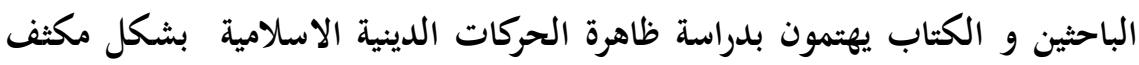
ومعمق (ا") ، وعلى الرغم من تشابه ظروف نشاة حركات الاسلام السياسي يؤكداتهيدر ابراهيم علي ) بان هذه الحركات تختلف في درجات تطورها واساليب عملها وعلاقاتها

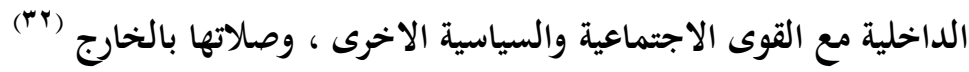

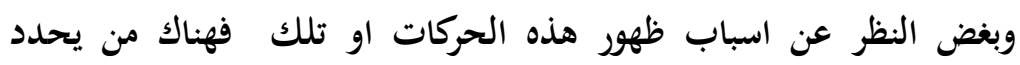
اهداف الفكر الحركي الاسلامي حسب وصفه بما يلي (بآ) : 1- مواجهة التيار الفكري اللاديني على المستوى الفردي وعلى المستوى لهي لئي

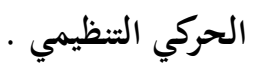
ץ- مواجهة الهجمة الفكرية التي رفعت شعار الإلحاد العلمي بمسميات الاشتراكية و القومية و غيرها. 
ץ- الاصلاح الذاتي على اساس تجديد الفكر الاسلامي و تحريك عجلة الاجتهاد . - الاد

ع - السعي لتحقيق الوحدة الاسلامية ، وهذا الهدف نابع من شمولية الدين

$$
\text { الاسلامي من جهة ونزعة التحرر فيه من جهة اخرى . }
$$

وهنا لابد من التعقيب على ما ورد في تحديد الاهداف انفة الذكر لاسيما

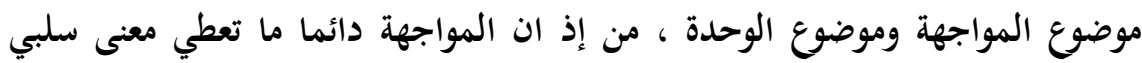

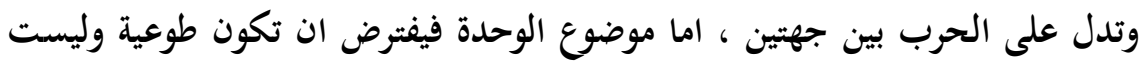

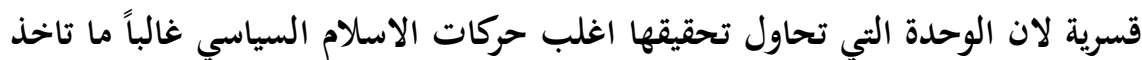
طابع العنف و الاجبار والتي من المفترض ان تكون قائمة على اساس الحوار و الطوعية وبطابع سلمي صرف .

لذلك نجد من يرى ان غالبية حركات الاسلام السياسي تستعمل العنف

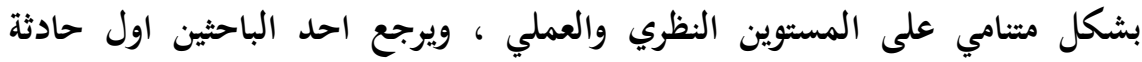

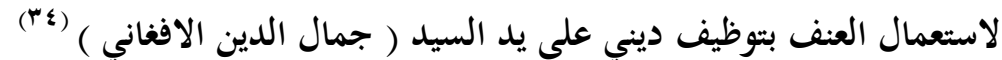
وفي المقابل لابد من القول ان هناك من يرفض فكرة توظيف الدين سين سياسياً

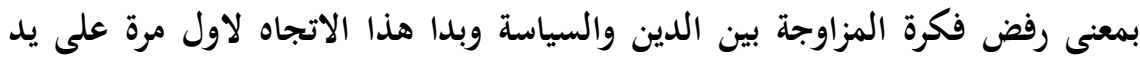

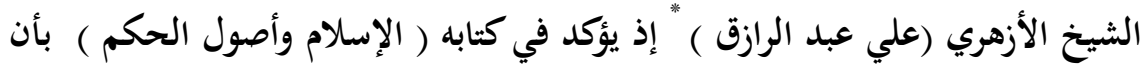

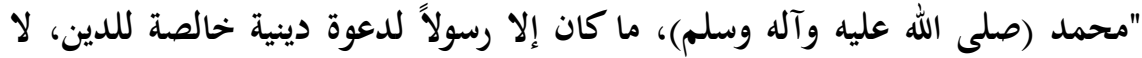
تشوبها نزعة ملك ولا حكومة، وانه (صلى الله عليه وآله وسلم)، لم يقم بتأسيس اله مملكة، بالمعنى الذي يفهم سياسة من هذه الكلمة ومرادفاتها، ما كان إلا رسولاً

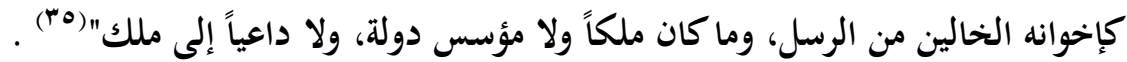
وهناك الكثير من المفكرين والباحثين الإسلاميين نحو منحى (علي عبد الرازق) في توجهه الفكري، أمثال خالد محمد خالد، ومحمود محمد طه، ومحمد لإسل احمد خلف الله، واحمد محمود صبحي، ومحمد سعيد العشماوي، وحسن حنفي، لهنه

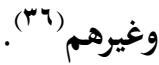


وبشكل عام يرى ( عزمي بشارة ) ان ظاهرة الاسلام السياسي أفرزت تيارين

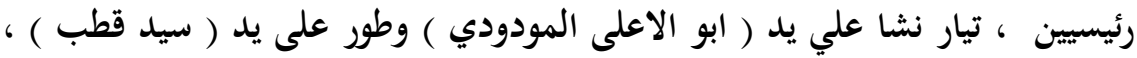

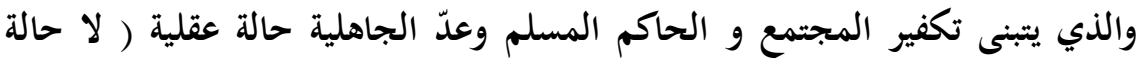
زمانية ) ، وتيار اخر نشا عند عدد من الحركات الاسلامية ( حركة راشد الغنوشي على سبيل المثال ) التي أخذت تعيش فترة ارتداد إصلاحي ، تحاول فيها البحث عن حلول

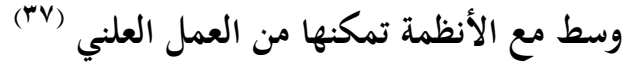

وهنا يذهب احد الباحثين الى ضرورة التمييز بين الدول الاسلامية المنشودة

والدولة الدينية من إذ ان الدولة الاسلامية يفترض ان تستمد سلطانها من الجماعة وهي

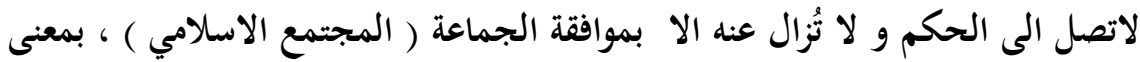
ليس للحاكم الاسلامي سلطة دينية يتلقاها من السماء كما كان يدعى بعض الحكام في

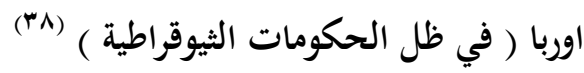

وبالرغم من كل الانتقادات الواسعة والحملات الاعلامية المضادة للحركات

التي تتبنى الاسلام السياسي الا انها تمكنت من ان تتحول الى قوة سياسية فاعلة في معظم البلدان العربية والاسلامية وان تثبت حضورها سواء بالفوز بالانتخابات وحصد اصوات تمكنها للسيطرة على السلطات التشريعية ( البرلمان ) ام الفوز بالحصول على لى لئل الرئاسة العامة ( السلطة التنفيذية ) . المحور الثالث : حركات الإسلام السياسي مقومات النجاح وأسباب الفشل. على الرغم من زخم نشاط حركات الاسلام السياسي في المنطقة العربية والاسلامية منذ منتصف السبعينات من القرن الماضي الا ان حظوظها في الميدان السياسي كانت متفاوتة ، في الجمهورية الاسلامية الايرانية استطاعت ان تستلم السلطة في وقت مبكر بعد الثورة ضد الشاه عام 9 و 9 م ، وفي الجزائر كادت جبهة الانقاذ ان تستولي على السلطة غير انها لم تستطع ان تقاوم الانقلاب العسكري الذي اوقف الانتخابات عام ب 99 1 م ، وفي العراق استطاعت حركات الاسلام الساسي ان

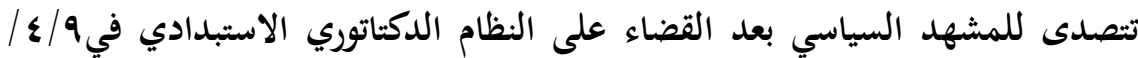


ץ +. بץ إذ ان نتائج الانتخابات الني جرت بعد ذلك افرزت الحصة الاكبر لاحزاب الاسلام السياسي ، وفي مصر استطاعت حركات الاسلام السياسي وهي تعد الاقدم من

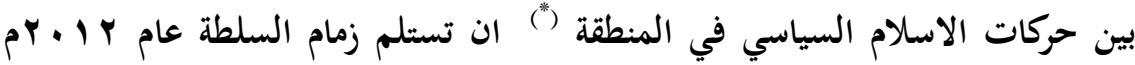
متمثلة بالرئيس محمد مرسي الذي هو اول رئيس منتخب بعد ثورة هب يناير الني جرت

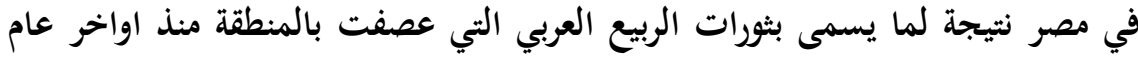

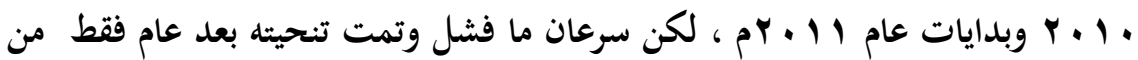

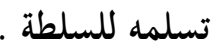
لذلك فان النجاح في الوصول للسلطة احياناً و الفشل في ادراتها احياناً اخرى تدل على وجود جملة من المقومات تساهم وتساعد حركات الاسلام السياسي من اجل الفوز في الانتخابات او استلام زمام السلطة السياسية في هذا البلد او ذاك ، وفي نفس الوقت يؤشر بوجود جملة من المعوقات التي تساهم في فشل الفوز او فشل

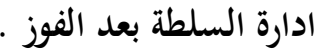
عند الحديث عن مقومات ومعوقات اي فكرة دائما ما نكون في اطار التقييم النسبي وليس المطلق ، لذلك فان الحديث عن مقومات نجاح حركات واحزاب

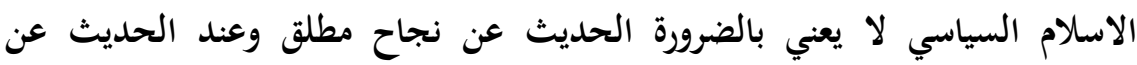

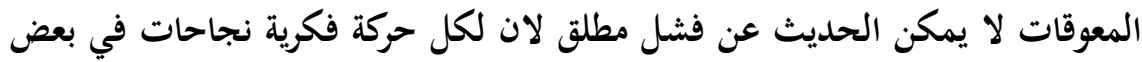
الاصعدة وفشل في اصعدة اخرى ، مما استوجب دراسة هذا المحور ضمن فقرتين · وقبل الدخول في تلك المقومات او المعوقات لابد من التوضيح بان الباحث ليس معنياً باصدار حكم قطعي حول فشل تيار او حركة ما او نجاح تيار او حركة ما ،

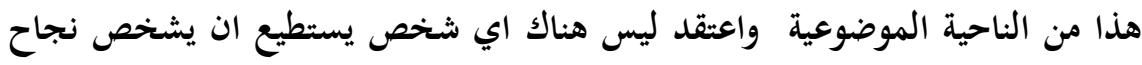
او فشل حركات الاسلام السياسي من الناحية العلمية و السبب ان الحديث عن حركات الاسلام السياسي هو الحديث عن ظاهرة سياسية متعددة الابعاد و الاتجاهات

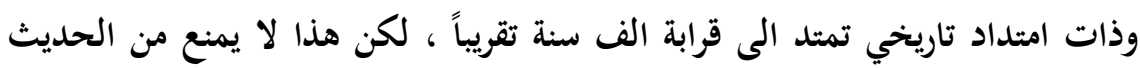
عن تلك الحركات بوصفها ترتكز على جملة من المقومات تساهم في تعزيز وجودها

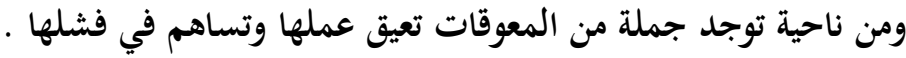




$$
\text { أولاً : مقومات نجاح حركات واحزاب الاسلام السياسي . }
$$

ان اغلب حركات واحزاب الاسلام السياسي تمثلك جملة من المقومات مما ساعدها في ان تصل للسلطة كما حدث في الجمهورية الاسلامية الايرانية و العراق وتركيا ومصر او الفوز بالانتخابات كما في فلسطين (حركة حماس ) و تونس او

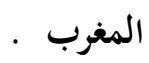

ولعل من ابرز المقومات ما يلي :

1-وجود نخب اكاديمية مثقفة .

استطاعت اغلب الحركات والاحزاب الاسلامية من ان تؤثر في شريحة واسعة من ابناء شعوبها لاسيما شريحة من المثقفين والاكاديميين ، إذ ان الكثير من الشهادات العليا و من مختلف الاختصاصات يتعاطفون او ينتسبون الى بعض من تلك الحركات المصنفه بـ(حركات الاسلام السياسي ) فمنهم الطبيب ومنهم

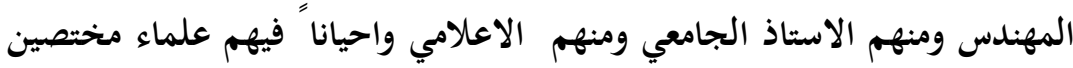
في علوم تتعلق بالتقنيات الحديثة كالحاسوب و الانترنت غيرها . ץ-وجود تاييد جماهيري واسع ·

لقد افرزت الممارسات الديمقراطية في البلدان الاسلامية تاييد واسعا لتيار الاسلام السياسي وابرز مثال على ذلك الانتخابات التي جرت وتجري في كل من

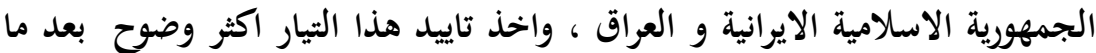
يعرف بثورات الربيع العربي في مصر وتونس ، وظهر تاييد هذا التيار ايضا خحلال الاصلاحات السياسي لبعض البلدان كما هو الحال في المغرب على سبيل لا

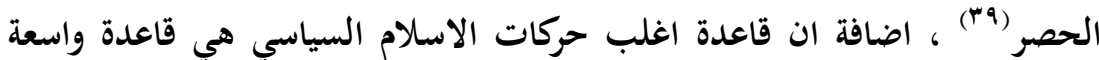
تتمثل بالفئات المتوسطة والفقيرة والتي لها اصوات انتخابية عددية غير قليلة (•) . . لذلك نجد ان حركات الاسلام السياسي اصبح لها تاييد ونفوذ شعبي استطاعت من خلالها التاثير في نتائج الانتخابات لتحصد عدد غير قليل من المقاعد 
الانتخابية ، اضافة الى تاثيرها في الاستفتاءات واخذت تضع لها بصمة واضحة في

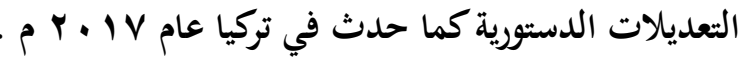

$$
\begin{aligned}
& \text { ب-وجود موارد مالية . }
\end{aligned}
$$

ان المتتبع لشؤون حركات الاسلام السياسي يجد بوضوح انها تمتلك موارد

مالية كبيرة نتيجة وجود عدد من التجار في صفوفها من جهة و وجود عدد من

$$
\text { ثانياً : معوقات نجاح حركات واحزاب الاسلى لهات لدمع اعضاءها من جهة اخرى . }
$$

على الرغم من كل مقومات النجاح التي تمتلكها حركات واحزاب الاسلام السياسي الا ان هناك جملة من المعوقات والتي ادت في بعض الاحيان الى فشل هذه الحركات في ادارة السلطة او تراجعها في الفوز بالانتخابات وتحقيق الاغلبية البرلمانية،

$$
\text { ولعل من ابرز اسباب الفشل ما يلي: }
$$

ا - اعدم التعامل بالواقعية السياسية.

ان ما يسجل على اغلب الحركات والاحزاب السياسية الاسلامية

انها نحت منحى عاطفى ارتجالي في التعامل مع الواقع السياسي المعاصر سواءا المحلي او الاقليمي او العالمي ، وعدم التعامل بواقعية سياسية نقصد به التعامل في اطار الطموح التي تحاول الوصول اليه تلك الحركات وهو حق مشروع لكن ذلك الطموح لا يمكن له ان يتحقق ما لم يقترن بواقعية سياسية تاخذ بنظر

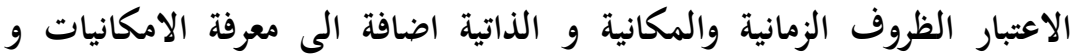
القدرات المتاحة والعمل وفق تلك الامكانيات و القدرات في التعامل مع الواقع الداخلي ( الشعبي ) و الواقع الخارجي ( الاقليمي او الدولي ) ، ففي احيانا كثيرة

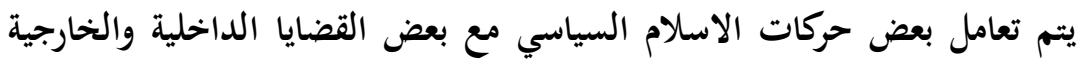
وفق معيار العاطفة و الاندفاع بحجة الغيره على الدين و الوطن وحفظ مصالحهما دون اعتماد معيار العقل و الحنكة السياسية التي تتطلب الصبر احياناً و المهادنة

$$
\text { و التفاوض في احيان اخرى . }
$$


r- ب الغلو والتطرف . - ب

على الرغم من وجود حركات للاسلام السياسي تنتهج الحوار و الطرق السلمية في تبليغ دعوتها وتطبيق متبنياتها الا ان من حركات الاسلام السياسي من انتهجت النهج المتشدد في التعامل مع المجتمع ، باعتبار هذه الحركات هدفها يتسم بالسمو والتقدس وهو تطبيق شريعة الله تعالى في الارض ، والمشكلة ليست في

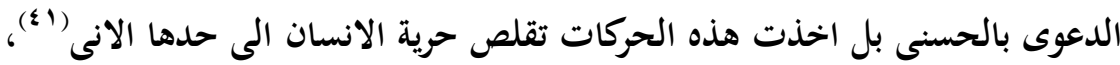

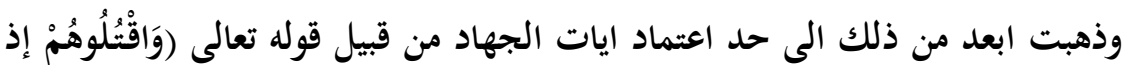

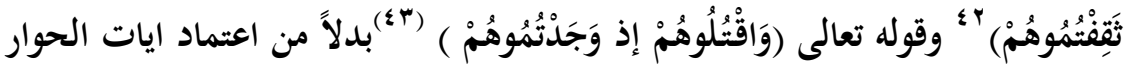

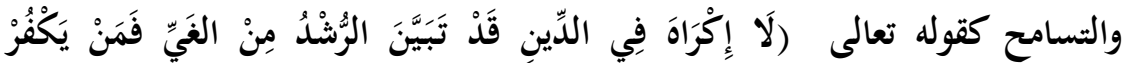

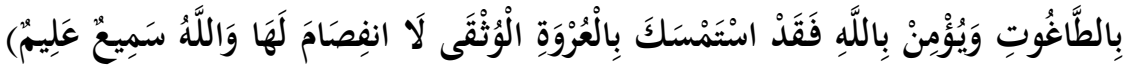

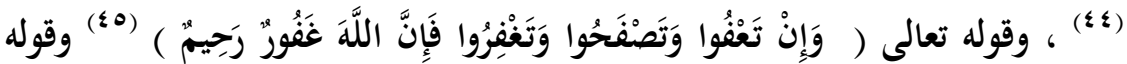

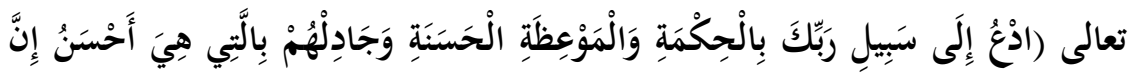

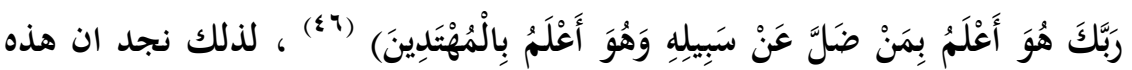
الحركات اخذت توظف جميع الايات القرانية و الاحاديث النبوية لغرض الدفاع عن لهن

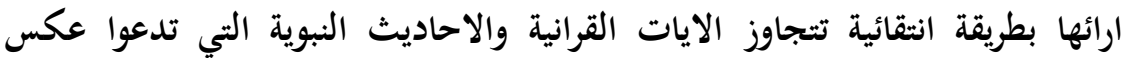

متبنياتها .

ب-تهميش الاحزاب والحركات الاخرى المنافسة .

على الرغم من دعوة غالبية حركات الاسلام السياسي الى اعتبار الديمقراطية تنطابق في الجوهر مع الشورى وذلك يجب الاخذ بها لغرض افساح المجال امام تبادل الاراء واخذ الراي السديد وعدم مصادرة اراء الناس في ما يريدون فعله او من خلال خياراتهم الانتخابية ، الا ان جوهر ما يؤمنون به لم يتضح

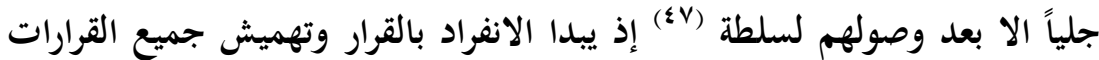

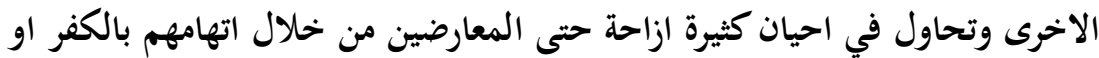


الخيانة وغيرها من التهم ، بمعنى اخر ان سلوكهم بعد استلام السلطة يتنافى مع

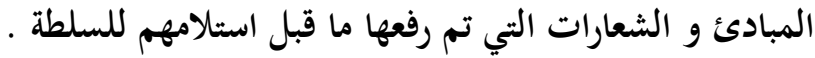
لذلك كانت من ابرز سماتها انها حركات منغلقة على نفسها ( التقوقع حول الذات)، إذ ان غالبية تلك الحركات لا ترى الا نفسها ولا تفهم الا ذاتها، وتنظر للمخالف نظرة دونية على اعتبار انه يسلك طريق الباطل وهم يسلكون طريق

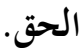
צ -عدم وضوح المنهج السياسي و الاقنصادي . ان الفوضى السياسية و الاقتصادية التي رافقت صعود عدد من حركات الاسلام السياسي في بعض البلدان جعلت المتابع لشان تلك الحركات يصل الى الى الى

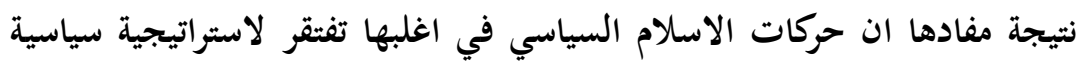

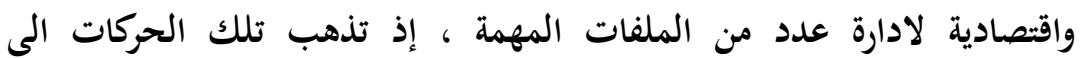
الاهتمام بالمظاهر الدينية المبالغ فيها في بعض الاحيان على حساب بناء متطلبات الدولة لاسيما البنى التحتية والموسساتية اضافة الى محاولة اثبات الحضور والعمل على الاعتماد على كوادرها السياسية حصرا دون الاستعانة

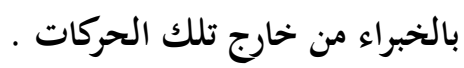

المحور الرابع : حركات الإسلام السياسي ، قراءة في ممارستها للسلطة . ان موضوع الإحاطة بكل حركات الإسلام السياسي ليس بالأمر اليسير ، لان تلك الحركات متعددة و مختلفة الى حد يصعب حصرها ضمن دراسة معينة لانها تقوم على

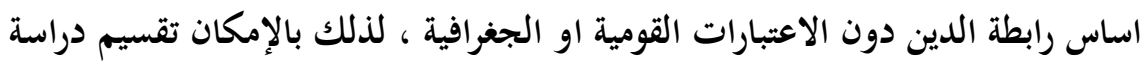
تلك الحركات في اطار هذا المحور على وفق ما يلي :

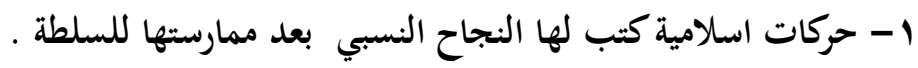

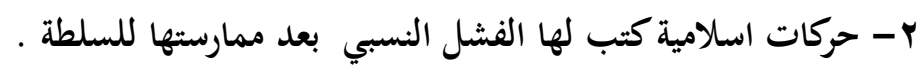
r- حركات اسلامية نجحت في جوانب وفشلت في اخرى بعد ممارستها للسلطة 
ان تصيف حركات الاسلام السياسي على حسب تجربتها في ادارة السلطة لا يحل

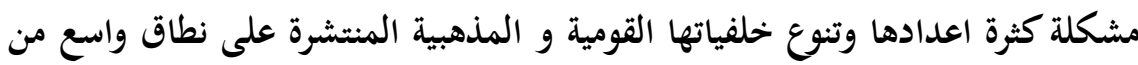
العالم ، لذلك يفترض ايضا اخذ نماذج مختارة لكل حالة .

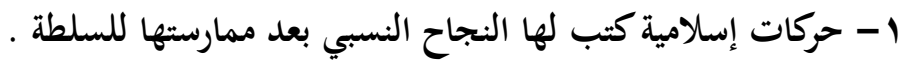
ان الحديث عن نجاح تجربة حركة إسلامية معينة في إدارة ممارسة السلطة لا

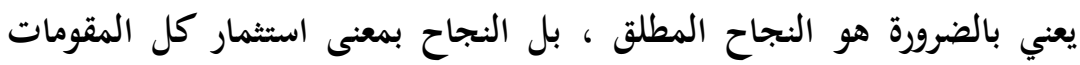
المتاحة بالحد المقبول من جهة و تحقيق نجاحات ملحوظة على المستوى

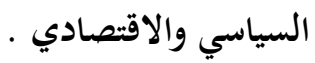
وبالإمكان القول ان حركات الإسلام السياسي في الجمهورية الإسلامية الإيرانية

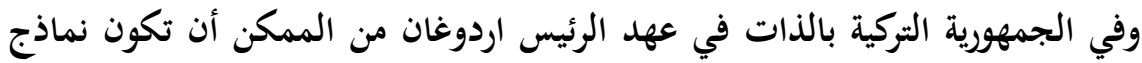

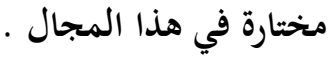
ففي الجمهورية الاسلامية الايرانية لا يخفى على المتابع لشان دول الشرق

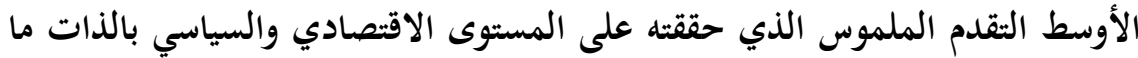

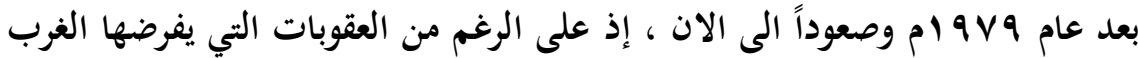
بسبب برنامجها النووي و موقفها الداعم للمقاومة ضد اسرائيل ، الا ان الجمهورية

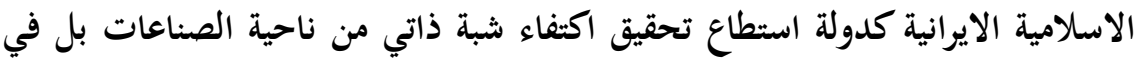
احيان اخرى تصبح مصدرة لعدد من المنتوجات الغذائية الضرورية او المنتوجات النفطية وبالذات للعراق و الدول المجاورة الاخرى ، وفي نفس الوقت استطاعت من ان تكون دولة لها ثقلها في المنطقة على المستوى الاقليمي و الدولي ، لاسيما وان ان الصناعات اخذت تتطور الى حد الحصول على الطاقة النووية السلمية كما تدعي و الغير سلمية كما تدعي دول الغرب . ونجاح الجمهورية الاسلامية الايرانية اقتصادياً لا يمنع من القول بانها كدولة بحاجة الى عمل المزيد في المجال السياسي لغرض استيعاب اكبر قد ممكن من الاراء

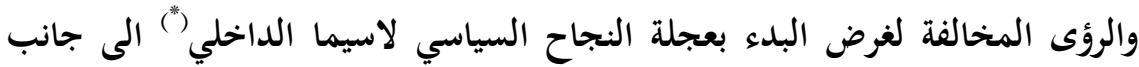
النجاح الاقتصادي المتحقق ل 
اما في الجمهورية تركيا فمن الممكن القول بوجود نجاح لحركات الإسلام السياسي في تركيا بالذات بعد سيطرة ( حزب العدالة والتنمية ) ما بعد عام Y . . Y م ، وقد وصف المراقبون للشان التركي وتيرة الاصلاحات الاقتصادية والسياسية ب( الثورة الصامته) ، إذ ساهمت الاصلاحات الاقتصادية في زيادة الاقتصاد التركي بشكل ملحوظ ، كذلك ساهمت الاصلاحات السياسية في زيادة الحضور التركي ونشاطه في

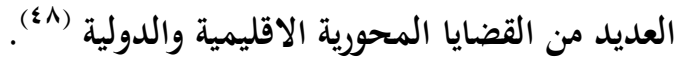
اما الحديث عن الجانب السياسي في الجمهورية التركية فالرغم من النجاح النداح النسبي لتركيا في السياسة الخارجية إذ اصبح لها موقع سياسي اقليمي مؤثر في سياسة

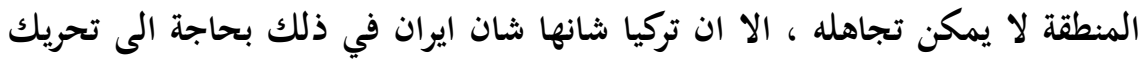
عجلة الاصلاحات السياسية الداخلية إذ ما يؤخذ على تركيا انها فشلت في استيعاب

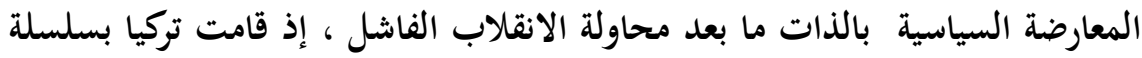
من الاجراءات ( اعتقالات ، فصل وظيفي ) بحق المعارضة جعلت موقفها السياسي

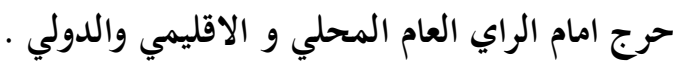

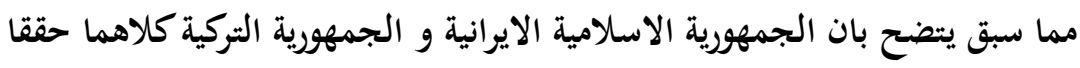

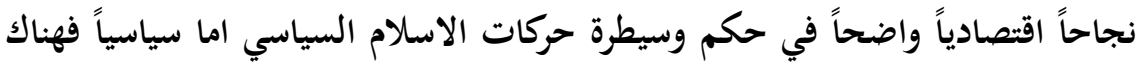
فشل على المستوى الداخلي و نجاح على المستوى الخارجي .

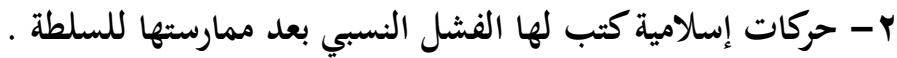
ان الفشل الذريع الذي منيت به حركة الاخوان المسلمين في مصر بعد سنة واحدة إندان تقريباً من استلامها للسلطة شكل نقطة فارقة وانتكاسة لحركة اسلامية تعدُ الاقدم في

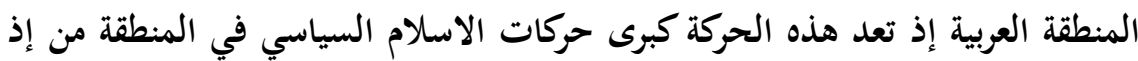

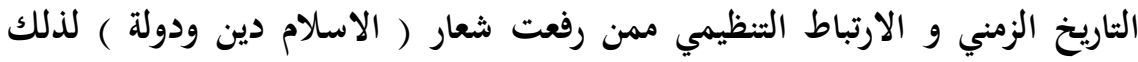

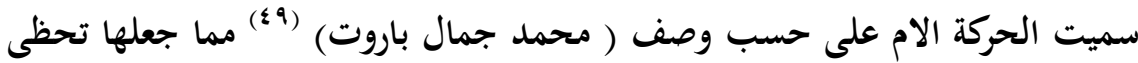

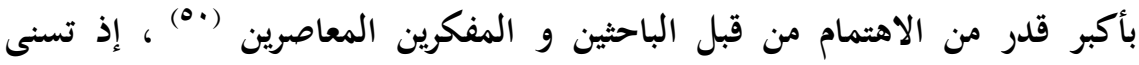
للاخوان المسلمين الوصول للسلطة في مصر بعد مرور اكثر من • ^ سنة في المعارضة (") الا انهم فشلوا في إدارة السلطة لكون من كان على راس السلطة ( الرئيس المعزول 
محمد مرسي ) ارتكب اخطاء كبيرة ناجمة عن قلة التجربة السياسية في الحكم و العقلية الانفرادية والتي اتسمت بطابع الاستئثار بالسلطة وعزل الاتجاهات والتيارات السياسية الاخرى (O) الانعراديه

واخذت اغلب الحركات الاسلامية تراجع نفسها نتيجة ذلك الفشل واخذت

الدراسات تبحث في اسباب ذلك الفشل الذي ارجعه البعض الى غياب القيادات

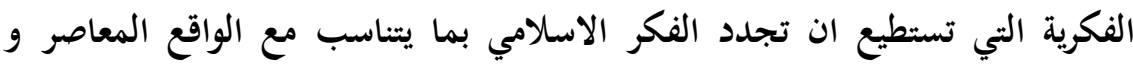
مجريات الامور المتغيرة نتيجة تغير الظروف الزمانية والمكانية والموضوعية بالقياس لما كان سابقاً في عصر الاسلام الاول . اخذت مصر تشهد تراجعا ملحوظاً لشعبية حركات الاسلام السياسي وبالذات لحركة الاخوان المسلمين بين افراد المجتمع المصري حتى المتدينين منهم بعد فشل سرسل تلك الحركة متمثلة بالرئيس المصري محمد مرسي الذي لم يدم حكمه اكثر من سنة واحدة ، إذ قطعت حركة الاخوان المسلمين عدد من الوعود للشعب المصري الذي يعيش عدد ليس قليل منه تحت خط الفقر ، لكنها لم تستطع ان توفي بآي منها .

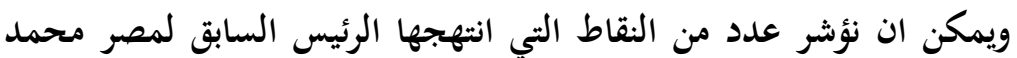
مرسي ساهمت بشكل مباشر او غير مباشر في انتهاء حكمه لعل من ابززها : 1- عدم التعامل بواقعية سياسية ذات بعد ستراتيجي مع عدد من من القضايا المهمة داخلية وخارجية ، ومن بين القضايا الداخلية هو عدم استيعاب موضوع الفن والفنانين والذين لديهم ثقل في المجتمع المصري ، عدم

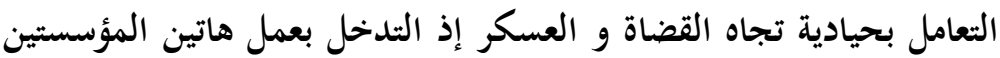

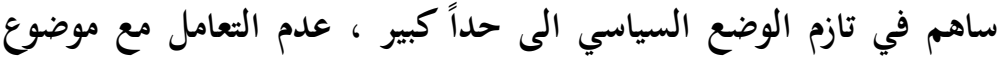
السياحة باعتباره مورد اقتصادي مهم لمصر بمعنى ضرورة المحافظة على تلى

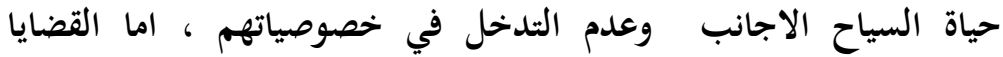
الخارجية فهي مهمة ومعقدة بحاجة الى بعد نظر في التعامل معها لا سيما موضوع العلاقة مع اسرائيل و التعامل مع بعض الجهات المصنفة بانها ارهابية و تستعمل العنف ضد الابرياء . 
r - عدم كسب ثقة الشارع المصري إذ تحولت في غضون عام فقط الرغبة الشعبية المؤيدة لحكم محمد مرسي و التي ساهم في صعود الاخوان المسلمين لسدة

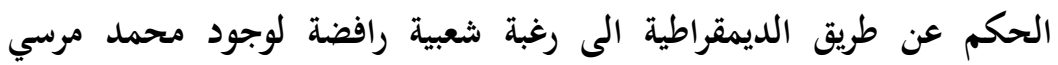
وتطالب بضرورة انهاء حكمه .

r- عدم تحقيق المشاركة السياسية الحقيقية بين الشركاء بعد تولي محمد مرسي

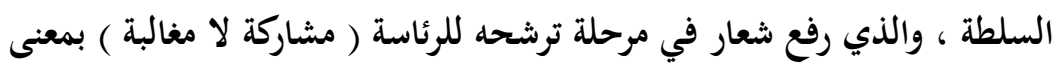

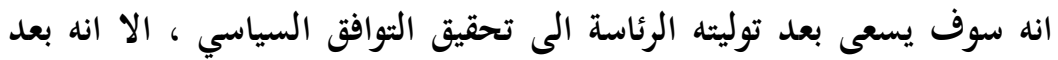

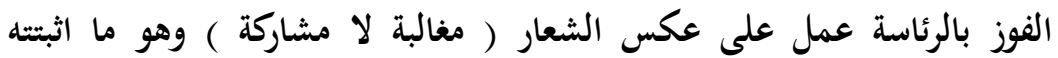

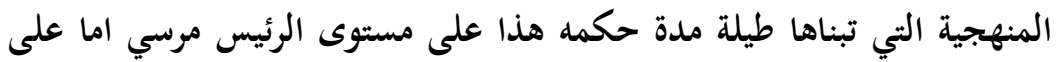

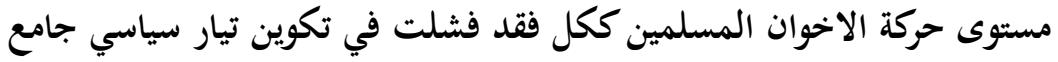
و أظهرت التجربة انهم غير قادرين على تجميع الصفوف والاتفاق مع الاحزاب

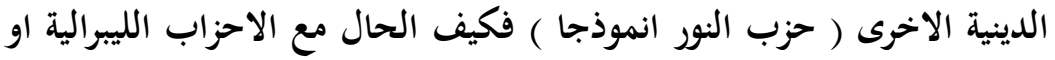

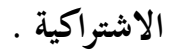

ع - عدم تعامل الاخوان المسلمين مع الوضع الجديد بصفة الحكم ومثطلباته بل تم

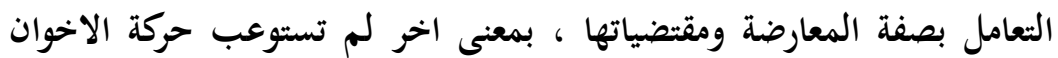
المسلمين طبيعة التغييرات التي جرت لاسيما وان للحكم شروطه ومستلزماته

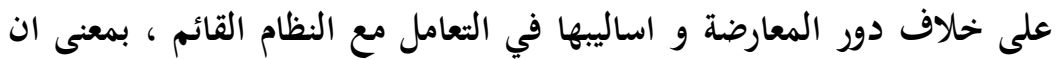
قيادات الاخوان المسلمين لم يغادروا فكرة انهم ضحية مؤامرات الدولة العميقة وضحية الاعلام المضلل و القوى العلمانية الخارجية والداخلية ، وظلت هذه الصورة طاغية على طيلة حكم ولم يتم التعامل مع الوضع الجديد بعقلية الدولة

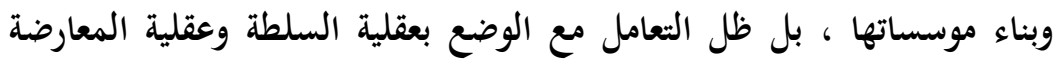

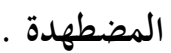
بمعنى اخر ان حركة الاخوان المسلمين لم تقرا الوضع الداخلي و الخارجي لمصر

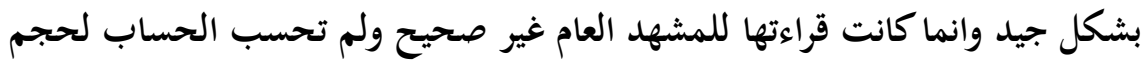
التحديات التي سوف تواجهها عندما تمسك بزمام السلطة ، لاسيما وان المجتمع 
المصري عاشت لمدة طويلة على نمط معين لا يمكن تغيير هذا النمط بين ليلة

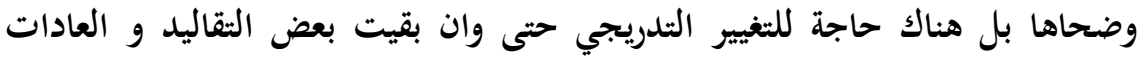

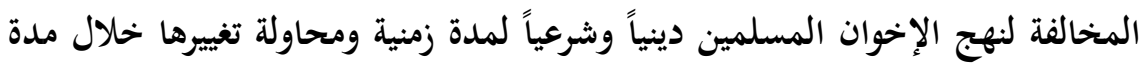
زمنية معينة تحددها طبيعة ظروف البلد السياسية و الاقتصادية و الاجتماعية . وفي عالم اليوم نجد ان اكبر مشكلة تواجه اغلب حركات الاسلام السياسي البارزة على الساحة الدينية و السياسية هو ادعاها بامتلاك الحقيقة المطلقة و احتكار تاويل

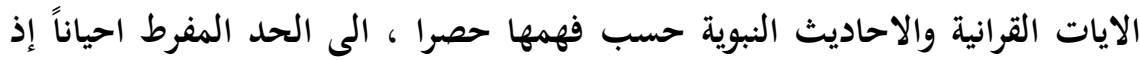

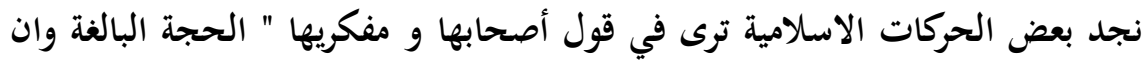

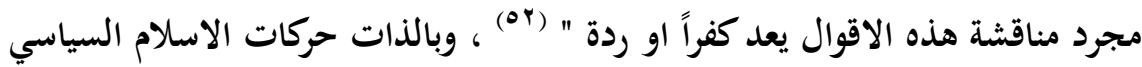
التي تاخذ من العنف وسيلة لتحقيق غايتها . ץ- حركات إسلامية نجحت في جوانب وفشلت في اخرى بعد ممارستها

$$
\text { للسلطة. }
$$

تعدُ حركات الاسلام السياسي في العراق من بين الحركات التي استطاعت ان تنجح في بعض الجوانب وتفشل في اخرى بعد استلامها

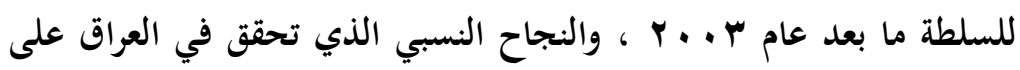
المستوى السياسي ممكن الحديث عن بعضاً منه بما يلي :

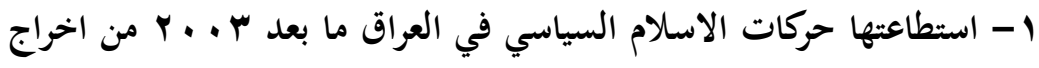

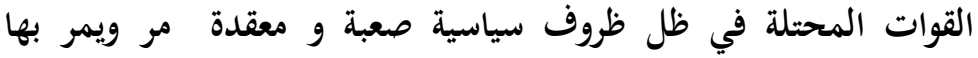

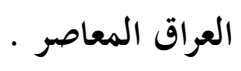
r- استطاعت حركات الاسلام السياسي في العراق من وضع دستور دائم للبلاد في ظل وضع سياسي منقسم غير منسجم ، و على الرغم من وجود

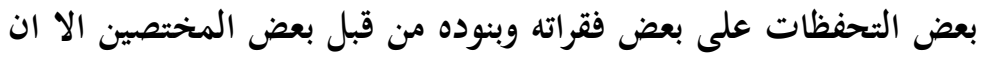
الشعب العراقي قد صوت عليه في اغلبيته وفق استفتاء عام جرى في العام 
ץ- اجراء اكثر من انتخابات ( نيابية- مجالس محافظات -استفتاء ) في ظل ظروف سياسية و أمنية صعبة جدا ، وهذه الانتخابات على الرغم من كل الملاحظات و الانتقادات التي وجهت حولها ، لابد من القول انها انجاز يُحسب لحركات الاسلام السياسي بعد ان كان العراق يعيش حالة الدكتاتورية في ظل النظام الاستبدادي السابق .

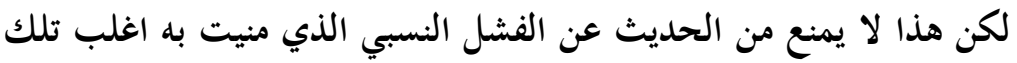

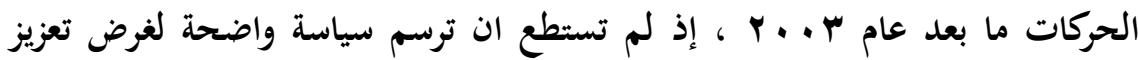
مؤسسات الدولة بل رسمت سياسة تعزيز مرتكزات السلطة ، وبناء السلطة دائما ما يشار له بانه مؤقت ولا يؤدي الى الاستقرار السياسي على العكس من بناء الدولة الذي يؤدي الى ديمومة النظام السياسي القائم ويساهم من جهة اخرى في تعزيز الاستقرار

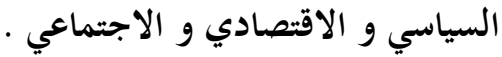

ولعل ابرز الاخفاقات و الفشل النسبي الذي حدث في العراق في ظل سيطرة

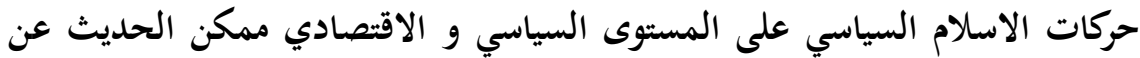

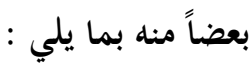

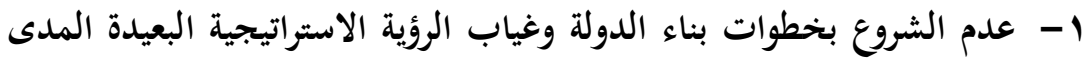
لمستقبل هذه الدولة المهمة في المنطقة و المؤثرة اقليمياً ودولياً . r- عدم استطاعت الاحزاب السياسية الدينية في العراق من تحقيق الؤية الموحدة للعراقيين بل ظلت كل جهة سياسة تنظر للاحداث من زواية الدين والقومية والطائفة بعيداً عن الؤية العراقية الوطنية الموحدة.

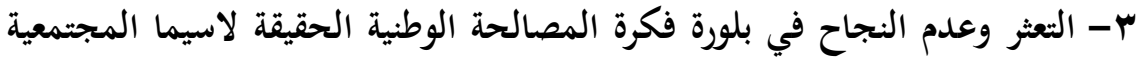

$$
\text { ع - غياب الهوية الوطنية على حساب الهويات الفرعية . }
$$

ه- عدم العمل وفق قاعدة الشخص المناسب في المكان المناسب ، بل بل واقع الحال

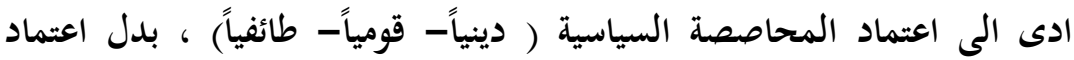
الخبرة والتخصص و الكفاءة . 
צ- بسبب المحاصصة والتوافقية لم تستطع حركات الاسلام السياسي من تحديد الجهة او الشخص المسؤول عن الفشل إذ الجميع يحاول ان يكون ممثل في السلطات الثلاثة بالذات التنفيذية على وجه الخصوص بطريقة غير منسجمة ومنظمة

وعدم الانسجام ربما سببه الرئيس هو التقاسم في السلطة بدل التشارك بها . V- فشلت حركات الاسلام السياسي في السيطرة على ادارة الموارد المالية الهائلة في العراق وعدم استثمار تلك الموارد وتمت اضاعة اغلبها في مشاريع فاشلة واخرى يشوبها الفساد الاداري و المالي . لمان. لكن لابد من القول لملاحظة مهمة من باب الموضوعية وليس الانفعالية ، ان

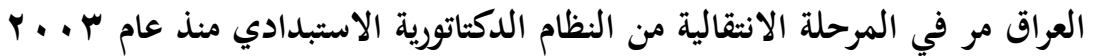
لغاية اليوم بظروف سياسية واقتصادية واجتماعية وامنية صعبة جدا لم يمر بها اي بلد في المنطقة ، لا سيما الهجمة البربرية من قبل العصابات الارهابية القاعدة

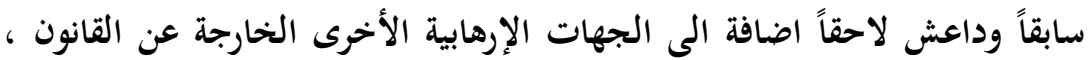
ففي ظل هذه الظروف لا يمكن تحديد الفشل و النجاح بسهولة ويسر ، بل

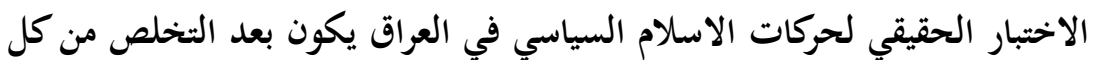
هذه العوائق لاسيما السياسية منها و الامنية . الخحاتمة والاستنتاجات

وسُجل على أغلب تلك الحركات (حركات الإسلام السياسي)،استخدامها

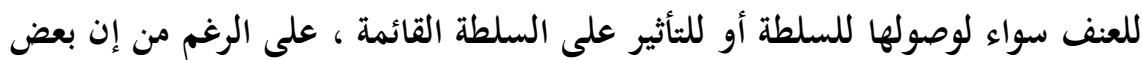
الحركات أخذت تسعى خلال الأعوام المنصرمة على تبني القيم الإنسانية والاجتماعية

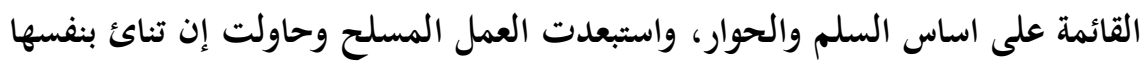
عن العنف، كما و تم الإعلان وعلى لسان الكثير من قيادات هذه الحركات عن إسقاطها للمطالبة، " بمشروع إقامة دولة إسلامية " ، إلا إن الكثير منها لازالت تعتمد بشكل أساسي ومباشر على إيديولوجية منغلقة، لا تقبل بالحوار الفكري والرأي الأخر. 
وعند قراءة الواقع المعاصر للإسلام السياسي لابد أولا من الإشارة إلى إن صعود الإسلام السياسي في بعض الدول العبية سواء التي طاولها التغيير السياسي في تونس ومصر وليبيا ، أو تلك التي تنتظر كما في اليمن والبحرين وسوريا، لم يكن مصادفة ولا حتى مفاجأة ، كونه نتاج الكثير من العوامل والظروف المحلية والدولية الذاتية والموضوعية ، وإذا ما بحثنا في الأسباب الذاتية المحلية ،فإننا نجد في مقدمتها سياسة الاستبداد والاستعباد التي مارستها تلك الأنظمة تجاه شعوبها ، والتي صادرت بها جميع الحقوق والحريات العامة والخاصة ، أما فيما يتعلق بالظروف والعوامل الدولية فهي كثيرة ومنها، العولمة والإرهاب الدولي، فضلا عن ذلك ، إن الولايات المتحدة الأمريكية ، تحاول فسح المجال إمام الأحزاب والحركات الإسلامية بغية

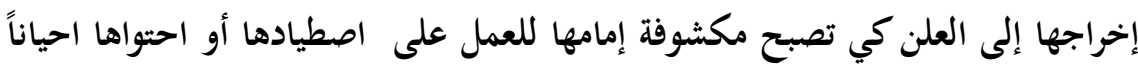
لذلك كانت ولازالت تسعى لإفشال مشروع الإسلام السياسي كونه البديل المحتمل

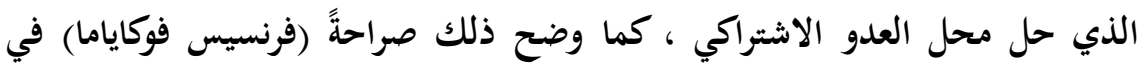
أطروحته " نهاية التاريخ ".

ولعل التحدي الأبرز لهذه الحركات الإسلامية سواء فازت بالأغلبية أم لا ، الأل ليس العمل على إثبات مشاركة الآخرين (المعارضة من العلمانيين والليبراليين)، والنهوض بالمؤسسات وحسب، بل الأهم من ذلك كله العمل على تطوير خطاب نهضوي يتلاءم مع طبيعة العصر.

$$
\text { وقد توصلت الدراسة الى جملة من الاستنتاجات لعل من أبرزها : }
$$

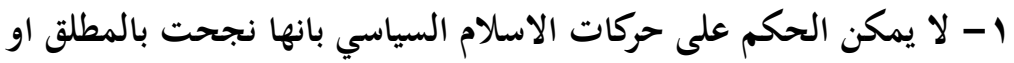

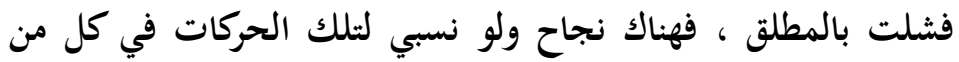
تركيا و جمهورية إيران الإسلامية في حين صفة الاخفاقات و الفشل غلب على الحركات في بعض البلدان وابرز مثال على الفشل ما حصل في مصر ، فالحديث عن ان حركات الاسلام السياسي بانها ناحجة او فاشلة حديث غير موضوعي ، بل الادق القول بان حركات الاسلام السياسي في هذا البلد او ذلك نجحت او فشلت بل يفضل تسمية 
الحركة نفسها التي استطاعت استثمار المقومات والتغلب على المعوقات

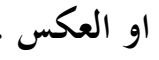

Y - إن الإسلام السياسي المعاصر وصل إلى نتيجة نهائية حتمية لابد منها ،

وهي ضرورة الاندماج بالواقع الجديد ، ومعرفة مطالب الثعوب العربية

ودراستها دراسة دقيقة ، وضرورة استثمار فرصة " ثورات الربيع العببي"،

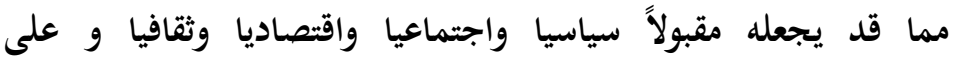
المستوى الوطني المحلي والإقليمي والدولي.

r- ان فشل حركة الاسلام السياسي المتمثلة بحركة الاخوان المسلمين في مصر مثل نقطة مهمة يجب التوقف عندها ، وهي لها تاثير مباشر سلباً على جميع حركات الاسلامي في المنطقة العربية ، حول ذلك هناك عدة احتمالات حول تاثير الفشل انف الذكر ، فهناك من يذهب الى ان الفشل هذا سوف يؤدي الى انحسار و تراجع حركات الاسلام السياسي

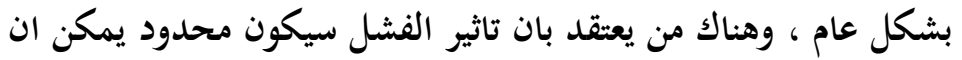
يقال انها بمثابة انحناءه مؤقتة سوف تعود بعدها حركات الاسلام

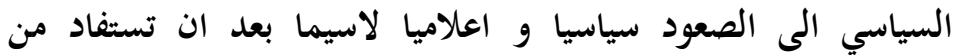
الاخطاء التي ساهمت في فشل التجربة في مصر بعد عزل الرئيس محمد

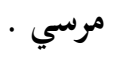

ع- ان حركات الاسلام السياسي بحاجة الى اجراء اصلاحات سياسية واقتصادية واجتماعية وثقافية على ذاتها ، وبدون هذه الاصلاحات سوف

$$
\text { تنتهي اما بالسجن او التفكك او العزلة ، او الفشل. }
$$

The concept of political Islam has many dimensions, which prevents its study within a narrow range, as it must be studied in a general study with passing on some selected models from These movements, and the observer of the political discourse today, especially in the countries of the Arab and Islamic world clearly finds a remarkable rise of the political movements of Islam, both in expanding its base and 
winning the votes of voters in some countries or access to power in other countries, in exchange for the decline and decline of currents Political competition (liberal currents, socialism and nationalism .(

And despite all the factors that contribute to the success of these movements and help in the spread and appearance, but that there are a number of obstacles contributed to and contribute to the failure of some of those movements and the reason for success and failure is determined by the extent of any movement of these movements benefit the available resources and the extent of the possibility of overcoming obstacles that you are facing

(1) د. خليل احمد خليل، معجم المصطلحات الدينية ، الطبعة الاولى ، دار الفكر اللبناني ، بيروت ، ه99 19، صه ץ.

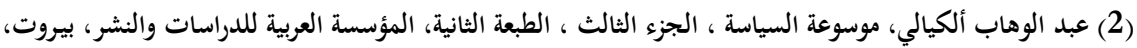

( ) د. دلي عباس مراد ، الخطاب السياسي الاسلامي و اشكالية المراوحة بين الشورى و الديمقراطية ، مجلة العلوم

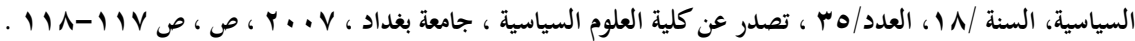

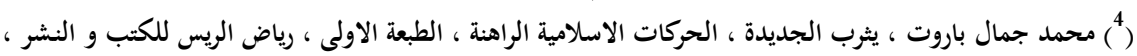

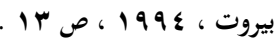
( ) رائد محمد عبد الفتاح ، اساليب التغيير السياسي لدى حركات الاسلام السياسي بين الفكر و الممارسة الاخوان

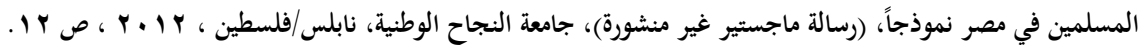

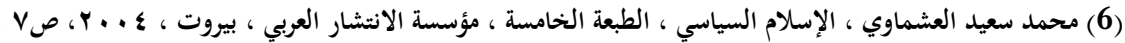

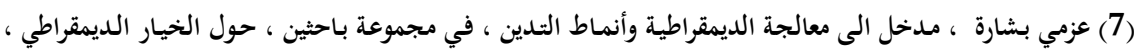

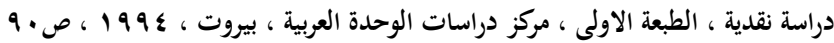

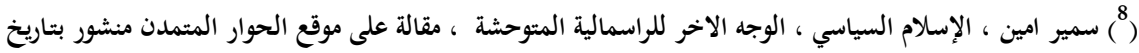

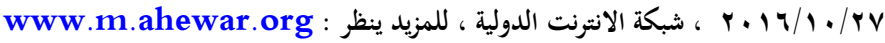

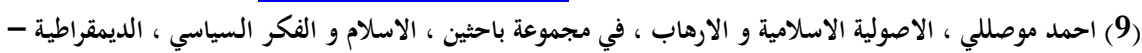

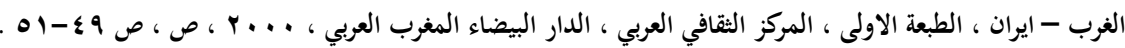

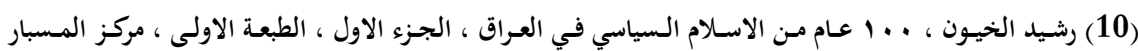

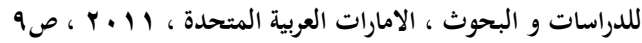

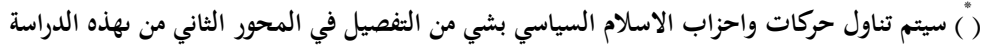

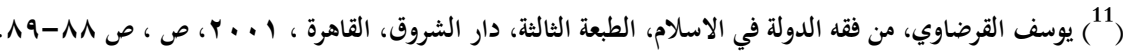

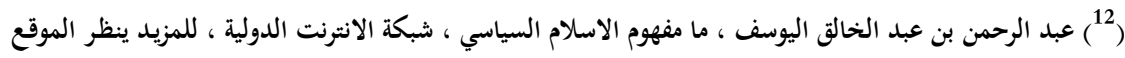
http://ar.islamway.com 


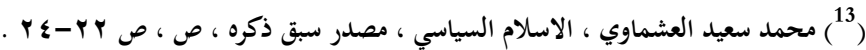

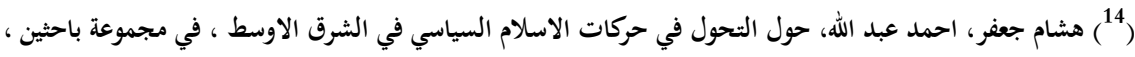

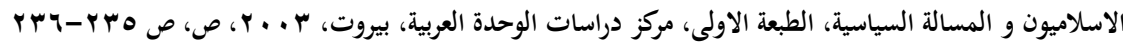

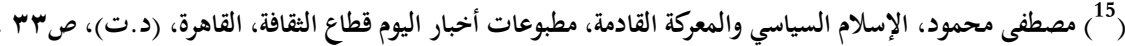

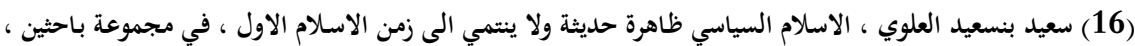

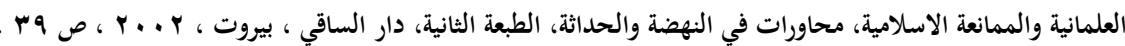

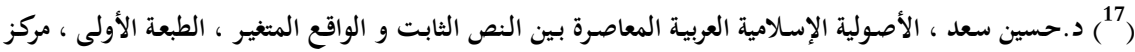

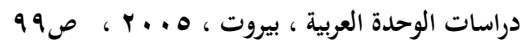

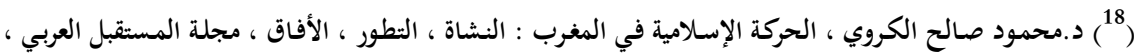

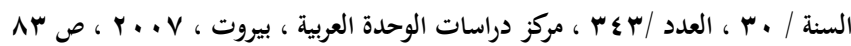

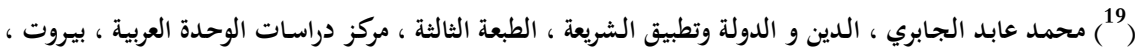
. $1 \leqslant 0$ ص r... 9

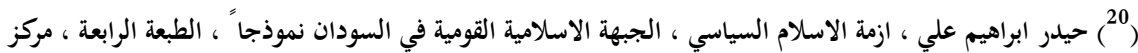

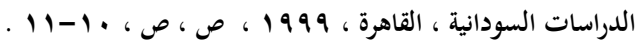

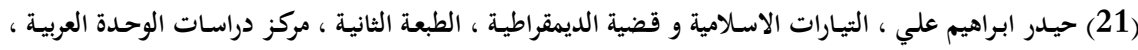

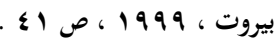

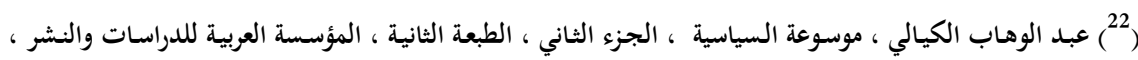

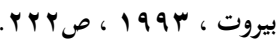

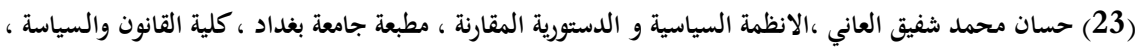
roO ص ، 1914

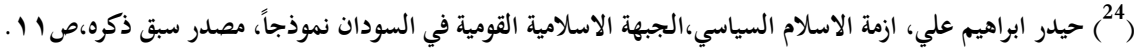

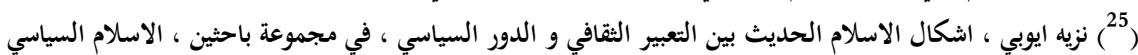

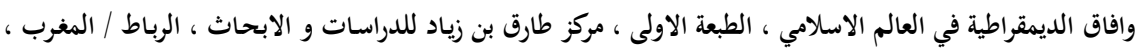
r r r...

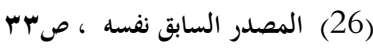

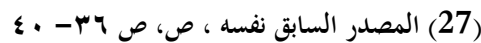

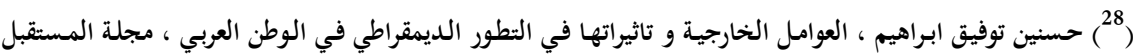

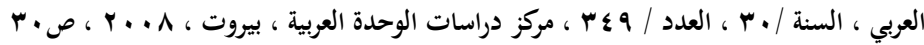

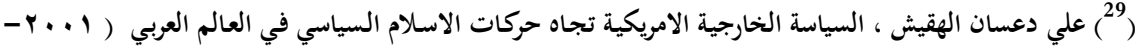

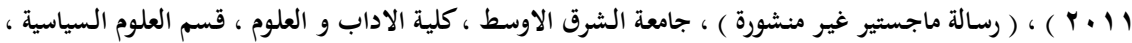

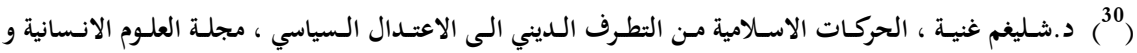

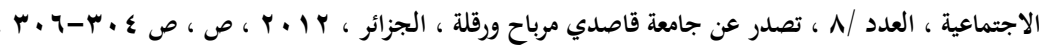

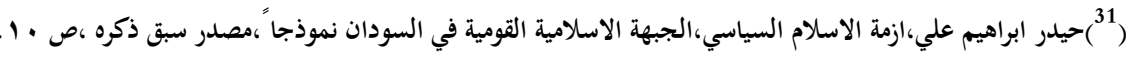


(32) حيدر ابراهيم علي ، التيارات الاسلامية و قضية الديمقراطية ، مصدر سبق ذكره ، صل؟ .

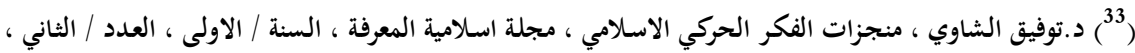

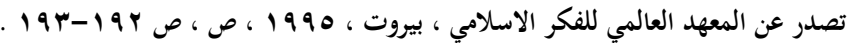

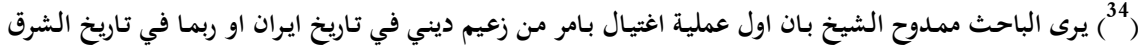

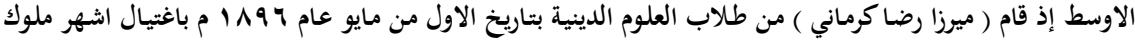

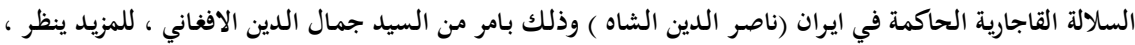

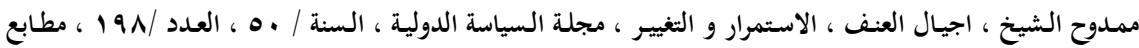

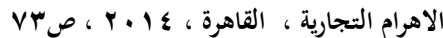
* ولد في قرية من قرى مصر الوسطى (المنصورة)، ولما بلغ العاشرة دخل إلى الأزهر إذ اتصل بالشيخ (محمد عبده)، وحضر بعض دروسه، وفي عام • (9 (م)، دخل الجامعة المصرية لمدة عامين، وحضر دروس (فلينو)، في تأريخ الأدب

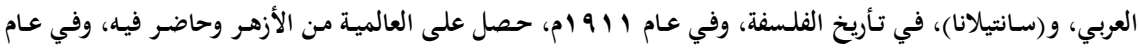

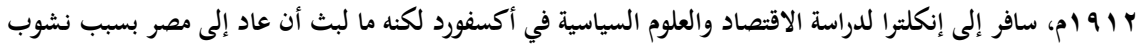

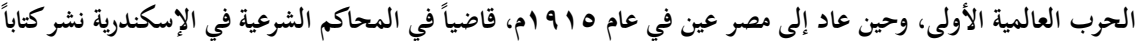

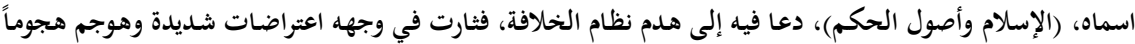

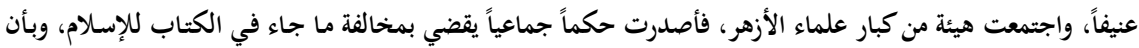

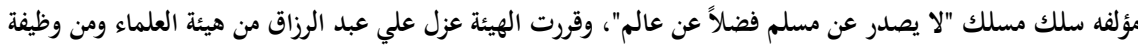
القضاء. انظر : فهمي جدعان، أسس التقدم عند مفكري الإسلام في العالم العببي الحديث، ، الطبعة الأولى، المؤسسة

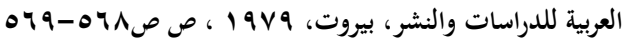

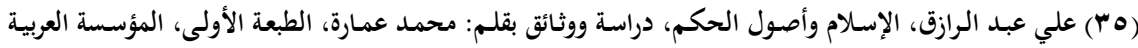

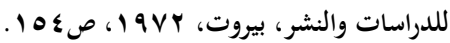

(36) للمزيد ينظر ، طارق عبد الحافظ الزبيدي ، الاسلام والعلمانية ، دراسة في ابرز الاتجاهات الفكرية السياسية صلامات

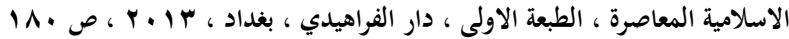

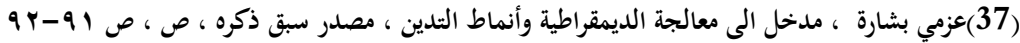

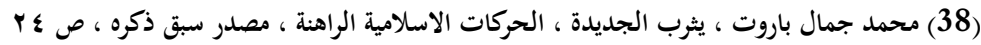

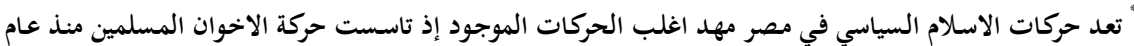

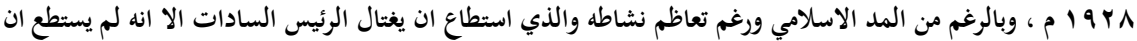
تستولي على السلطة في تلك المدة : للمزيد ينظر ، جيل كيبل ، من اجل تحليل اجتماعي للحركات الاسلامية ، في

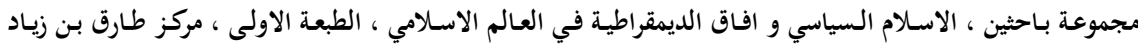

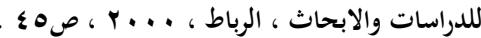

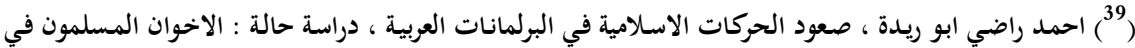

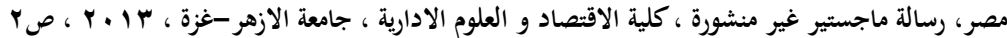

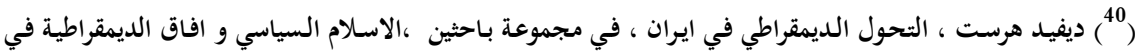

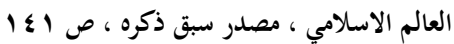




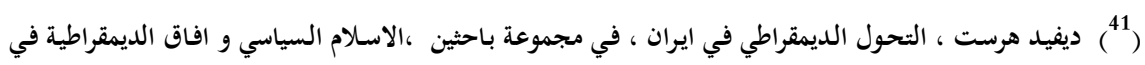

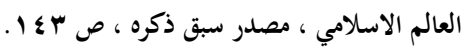

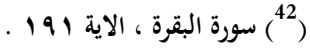

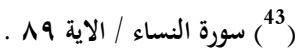

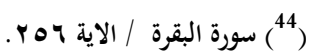

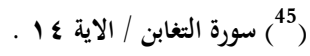

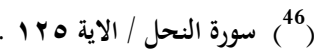

(47) ديفيد هرست ، التحول الديمقراطي في ايران ، في مجموعة باحثين ، الاسلام السياسي و افاق الديمقراطية في

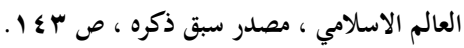

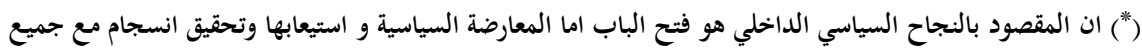

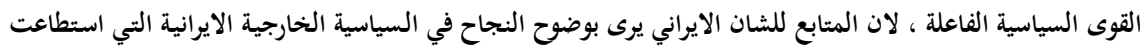

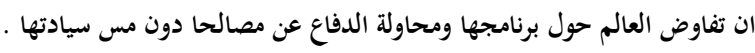

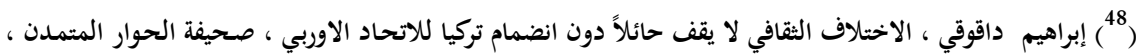

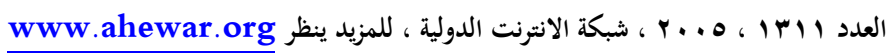

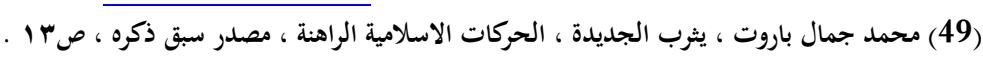

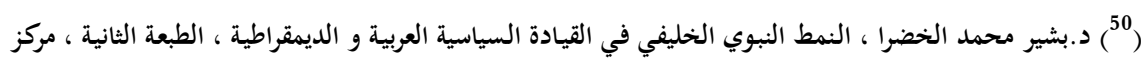

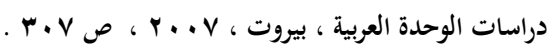

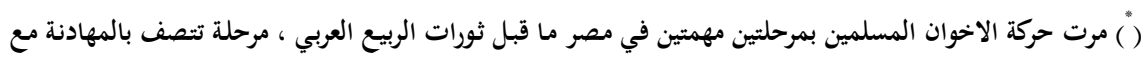

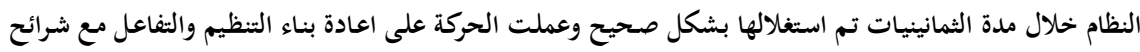

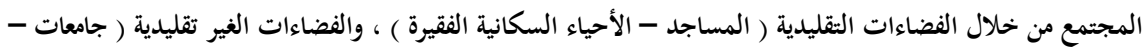

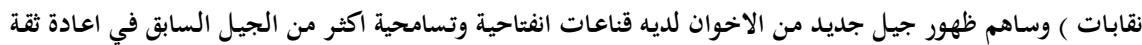

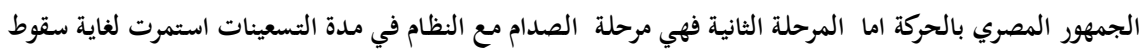

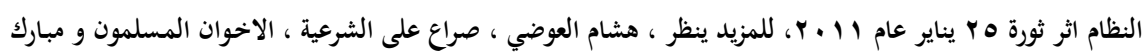

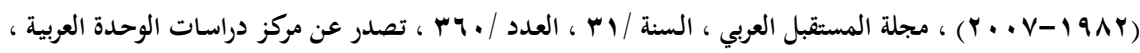

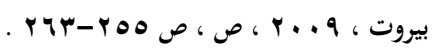

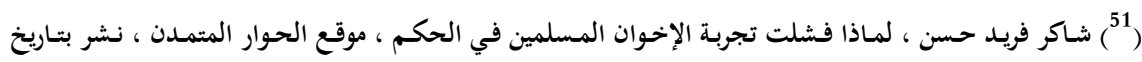

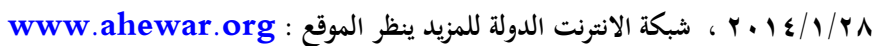

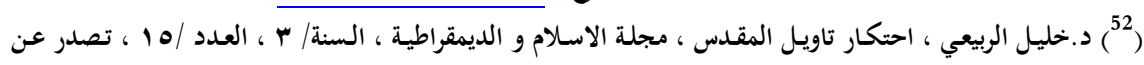

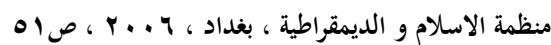

